Review

\title{
Recent Synthetic Approaches Toward Non-anomeric Spiroketals in Natural Products
}

\author{
Sylvain Favre, Pierre Vogel and Sandrine Gerber-Lemaire*
}

Laboratory of Glycochemistry and Asymmetric Synthesis, Ecole Polytechnique Fédérale de Lausanne, Batochime, CH-1015 Lausanne, Switzerland

* Author to whom correspondence should be addressed; E-mail: Sandrine.Gerber@epfl.ch.

Received: 18 July 2008; in revised form: 29 September 2008 / Accepted: 15 October 2008 / Published: 17 October 2008

\begin{abstract}
Many natural products of biological interest contain [6,5]- and [6,6]-spiroketal moieties that can adopt various configurations, benefiting or not from anomeric conformation stabilizing effects. The spiroketal fragments are often important for the biological activity of the compounds containing them. Most stable spiroketal stereoisomers, including those benefiting from conformational anomeric effects (gauche conformers can be more stable than anti conformers because of a contra-steric stabilizing effect), are obtained easily under acidic conditions that permit acetal heterolysis (formation of tertiary oxycarbenium ion intermediates). The synthesis of less stable stereoisomers requires stereoselective acetal forming reactions that do not permit their equilibration with their most stable stereoisomers or, in the case of suitably substituted derivatives, concomitant reactions generating tricyclic products that quench the less stable spiroketal conformers. Ingenuous approaches have been recently developed for the synthesis of naturally occurring [6,6]- and [5,6]-nonanomeric spiroketals and analogues. The identification of several parameters that can influence the stereochemical outcome of spirocyclization processes has led to seminal improvements in the selective preparation of the non-anomeric isomers that are discussed herein. This review also gives an up-dated view of conformational anomeric effect which represents a small fraction of the enthalpic anomeric effect that makes gem-dioxy substituted compounds much more stable that their 1,n-dioxy substituted isomers $(\mathrm{n}>1)$. Although models assuming $\mathrm{sp}^{3}$-hybridized oxygen atoms have been very popular (rabbit ears for the two non-bonding electron pairs of oxygen atom), $\mathrm{sp}^{2}$-hybridized oxygen atoms are used to describe the conformational anomeric effect.
\end{abstract}


Keywords: Spiroketal, anomeric interaction, non-anomeric interaction, thermodynamic equilibration, kinetic control, spirocyclization, anomeric effect, gauche effect.

\section{Introduction}

Spiroketals and in particular 6,6-congeners are key structural features of a variety of natural products of biological interest which include marine macrolides, ionophores and polyether antibiotics [1]. For instance, spongistatins (altohyrtins), which were isolated from marine sponges of the genus Spongia by three research groups in 1993, present two highly functionalized 6,6-spiroketal subunits in their skeleton (Figure 1) [2]. Interestingly, while the AB spiroketal adopts a (gauche, gauche)conformation and thus benefits from a double conformational anomeric effect (two axial C-O moieties in chair tetrahydropyran rings), the CD spiroketal stands in a (anti, gauche)-conformation benefiting from a single anomeric effect (one $\mathrm{C}-\mathrm{O}$ of one tetrahydropyran ring in axial position with respect to the other ring). Most of the methodologies that have been developed for the synthesis of spiroketals are based on acid catalyzed spirocyclization of dihydroxy-ketone precursors which generally lead to the most stable stereoisomers and conformers. The obtention of the less stable spiroketals (gauche, anti or anti, anti) requires either the reversal of the thermodynamic stability by additional stabilizing interactions such as hydrogen bonding or a kinetic control for the formation of the spiroketal. This review will highlight the recent strategies [3] that have been developed for the selective synthesis of spiroketals in natural products, with particular emphasis on the $\mathrm{AB}$ and $\mathrm{CD}$ subunits of spongistatins / altohyrtins.

Figure 1. Members of the spongistatins/altohyrtins family.
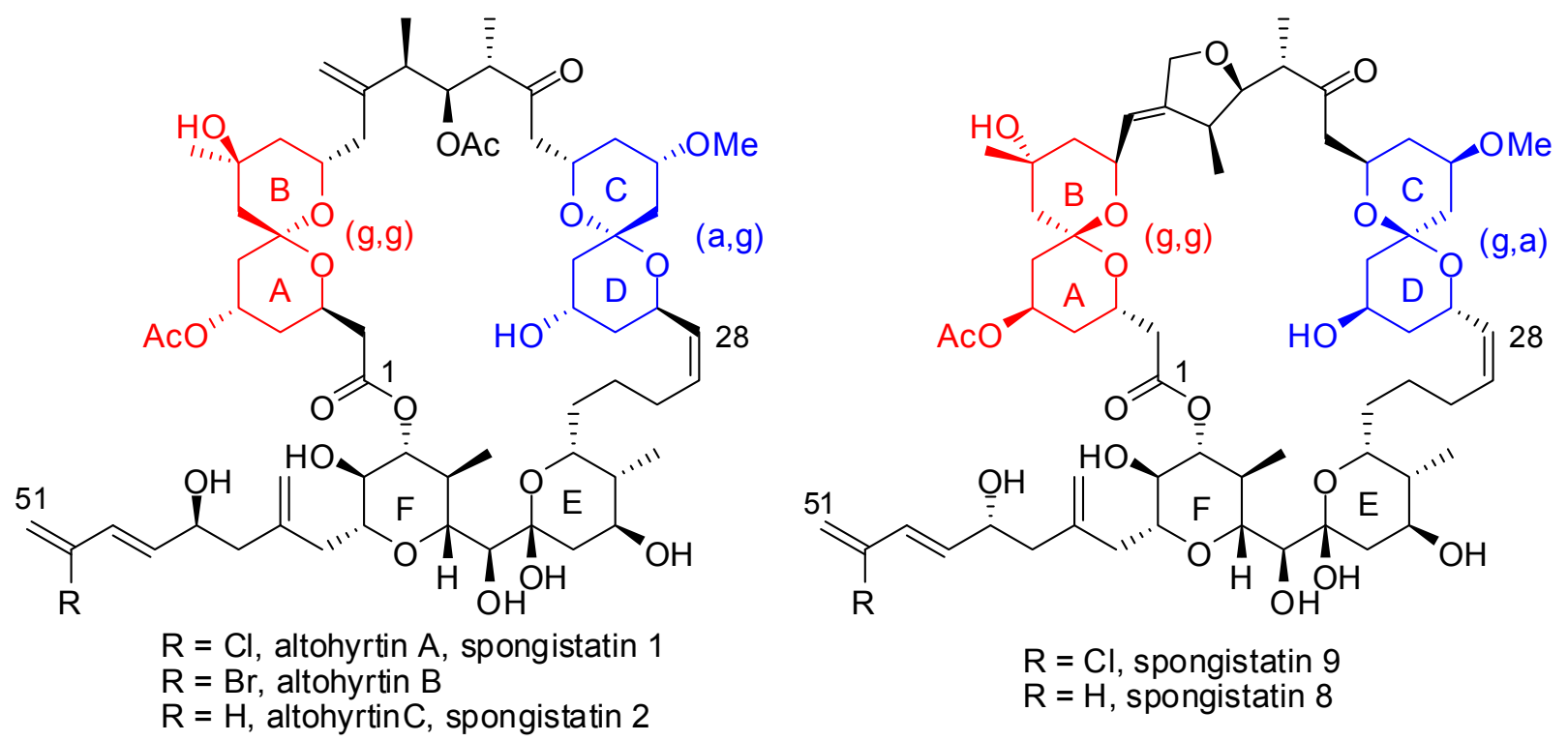


\section{Relative stability of spiroketal stereoisomers and conformers}

Acetals are more stable than their 1,n-dialkoxyalkane isomers $(n>1)$. Examples are given by comparing the standard heats of formation (gas phase) of 1,2-diethoxyethane $\left(\Delta \mathrm{H}_{\mathrm{f}}{ }^{\circ}=-98.0 \mathrm{kcal} / \mathrm{mol}\right)$ with that of 1,1-diethoxyethane $\left(\Delta \mathrm{H}_{\mathrm{f}}{ }^{\circ}=-108.4 \mathrm{kcal} / \mathrm{mol}\right)$, of 1,3-diethoxypropane $\left(\Delta \mathrm{H}_{\mathrm{f}}{ }^{\circ}=-104.3\right.$ $\mathrm{kcal} / \mathrm{mol})$ with that of 2,2-diethoxypropane $\left(\Delta \mathrm{H}_{\mathrm{f}}^{\circ}=-121.1 \mathrm{kcal} / \mathrm{mol}\right)$, or of 1,4-dioxane $\left(\Delta \mathrm{H}_{\mathrm{f}}{ }^{\circ}=-75.4\right.$ $\mathrm{kcal} / \mathrm{mol})$ with that of 1,3 -dioxane $\left(\Delta \mathrm{H}_{\mathrm{f}}{ }^{\circ}=-80.9 \mathrm{kcal} / \mathrm{mol}\right)$. The gem-dioxy substitution stabilizing effect is called the "enthalpic anomeric effect" [4]. Known for alkyl pyranosides since 1905 (e.g.: alkyl $\alpha$-D-glucopyranosides being more stable than their $\beta$-anomers) [5] and rediscovered in 1955 by Edward [6], and by Lemieux and Chü in 1958 [7], the conformational anomeric effect designs the contra-steric effect observed in acetals which renders the more sterically encumbered gauche/gauche conformers (1) more stable than their anti/gauche (2) and anti/anti (3) conformers (Figure 2). [IUPAC defines prefix anti (antiperiplanar) for two vicinal $\sigma$ bonds making a dihedral angle $150<\theta<210^{\circ}$, and prefix gauche for two vicinal $\sigma$ bonds making a dihedral angle $30<\theta<90^{\circ}$ ].

Figure 2. Possible conformations of hemiacetals and acetals.

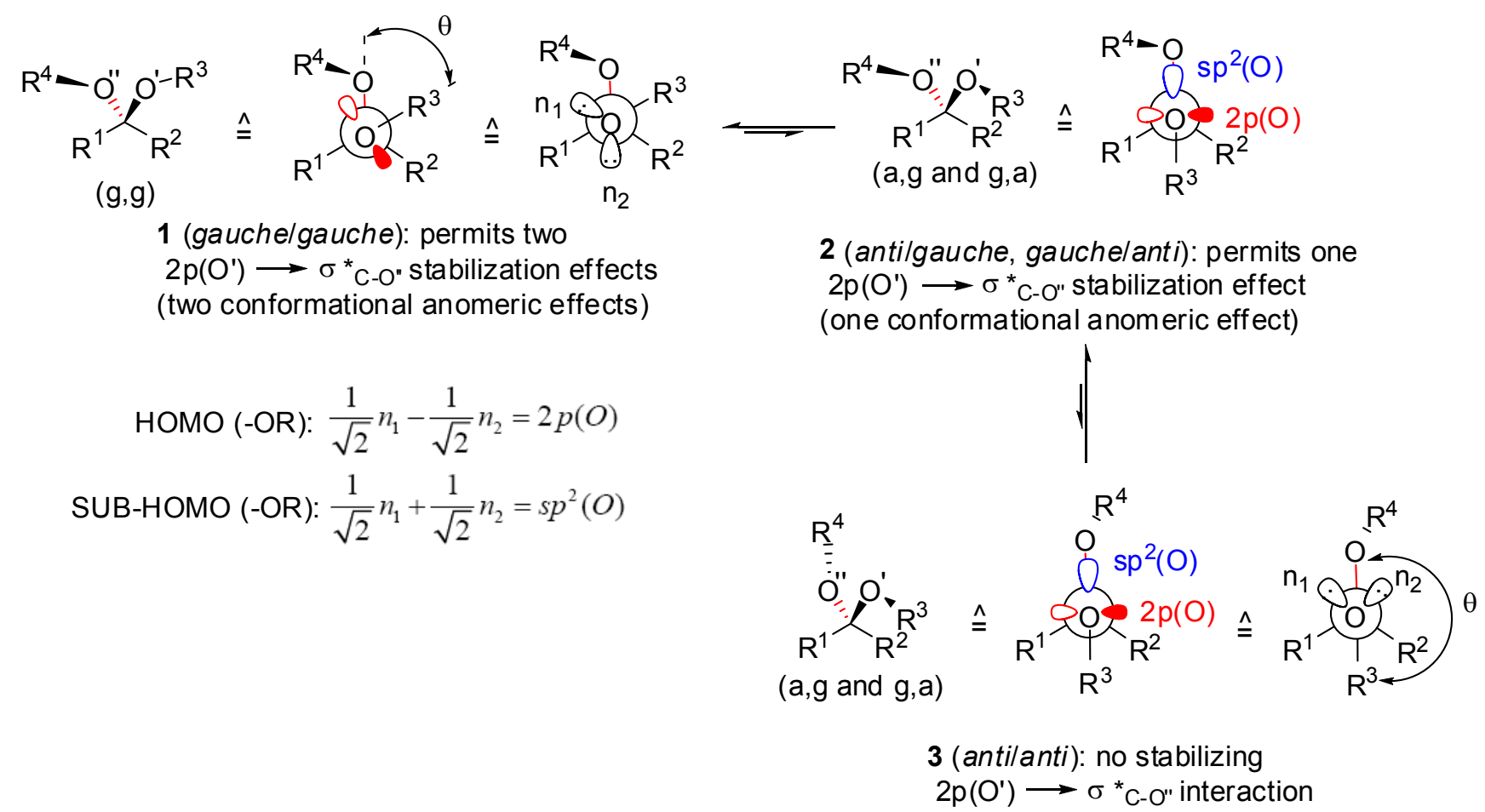

The conformational anomeric effect explains the higher stability of alkyl $\alpha$-D-glucopyranosides with respect to their $\beta$-anomers and the exo-anomeric effect in these compounds [8]. It has been ascribed to $\sigma$ conjugation [9] of the type $2 \mathrm{p}\left(\mathrm{O}^{\prime}\right) \rightarrow \sigma^{*}{ }_{\mathrm{C}-\mathrm{O}}$ ", (negative hyperconjugation). ${ }^{10}$ Similar effects were proposed by Deslongchamps and co-workers to intervene on the stability difference of 1,7-dioxaspiro[5.5] undecanes (6,6-spiroketals) [11]. Differences in stability between acetal conformers (or stereoisomers) benefiting from possible hyperconjugation interactions $2 \mathrm{p}\left(\mathrm{O}^{\prime}\right) \rightarrow \sigma^{*}{ }_{\mathrm{C}-\mathrm{O}}$, and those in which these stabilizing effects are prohibited by their geometry $\left(2 \mathrm{p}\left(\mathrm{O}^{\prime}\right)\right.$ orbital perpendicular to the 
empty $\sigma^{*}$ C-O" orbital) is only a fraction $(-1$ to $-3 \mathrm{kcal} / \mathrm{mol})$ of the global enthalpic anomeric effect or gem-dioxy stabilizing effect (-6 to $-17 \mathrm{kcal} / \mathrm{mol})$. Dipole/dipole stabilizing interactions intervene also in hemiacetals, acetals and ketals (acetals derived from ketones). Depending on substitution, steric factors can affect the relative stability of acetal conformers [4c,12]. Differences in stability between acetal conformers of type 1, 2 and $\mathbf{3}$ are also solvent dependent [13]. For instance, 2-hydroxytetrahydropyran prefers an axial hydroxyl group in the gas phase and in non polar solvents [14] whereas it prefers an equatorial hydroxyl group in aqueous solution [15]. In many instances, a $\mathrm{sp}^{3}$-hybridized oxygen atom is used to describe the properties of acetals (with two $\mathrm{sp}^{3}$ orbitals occupied each by two electrons pairs: rabbit ears). This model is reminiscent of the banana bonds model used sometimes to interpret properties of $\pi$ systems such as alkenes and carbonyl moieties. Electron distribution about oxygen atom in $\mathrm{H}_{2} \mathrm{O}$ [16], ethers and related compounds are better represented by using a $\mathrm{sp}^{2}$ hybridized oxygen atom [17]. In fact $\operatorname{sp}^{2}(\mathrm{O})$, the SUB-HOMO is equivalent to the combination $1 / \sqrt{ } 2$ $\mathrm{sp}^{3}(\mathrm{O})+1 / \sqrt{ } 2 \mathrm{sp}^{3}(\mathrm{O})$ and the HOMO, localized on the ethereal oxygen atom is equivalent to $1 / \sqrt{ } 2$ $\mathrm{sp}^{3}(\mathrm{O})-1 / \sqrt{ } 2 \mathrm{sp}^{3}(\mathrm{O})$. As the latter is higher in energy than the former localized orbital, it contributes more efficiently to any electron transfer, for instance into a hyperconjugated $\mathrm{C}-\mathrm{X}$ bond. We thus prefer to use $\mathrm{sp}^{2}$-hybridized than $\mathrm{sp}^{3}$-hybridized oxygen atoms in spiroacetals. Moreover, the analysis of the crystal structures of [6,6]-spiroketal derivatives recorded in the Cambridge Structural Database revealed that the dihedral angle $\theta$ (Figure 2) defined by the $\mathrm{O}-\mathrm{C}, \mathrm{O}-\mathrm{C}$ bonds of the spiroketals is larger than $60^{\circ}$ in most cases (mean value: $62^{\circ}$ for 84 [6,6]-(gauche/gauche)-spiroketal structures). This observation is in agreement with the $\mathrm{sp}^{2}(\mathrm{O})$ model depicted in Figure 2 for the conformational anomeric effect which intends to optimize overlap between $2 \mathrm{p}(\mathrm{O})$ (HOMO) and $\sigma^{*}{ }_{\mathrm{C}-\mathrm{O}}$ (LUMO) orbitals . Recent quantum calculations and topological analysis using the Quantum Theory of Atoms in Molecules (QTAIM) [16] provide an explanation of the conformational anomeric effect for acetals that is not in line with the $\mathrm{n}(\mathrm{O}) \rightarrow \sigma^{*}{ }_{\mathrm{C}-\mathrm{O}}$ hyperconjugation model. The conformational energy variations are accompanied by an electron population redistribution that implies the $\mathrm{CH}_{2}$ group in $\mathrm{MeOCH}_{2} \mathrm{OMe}$, and by extension the $\mathrm{CR}^{1} \mathrm{R}^{2}$ group in other acetals. The stabilization of the gauche conformers of $(\mathrm{MeO})_{2} \mathrm{CH}_{2}$ is accompanied by a progressive reduction of the electron population of the hydrogens of the central $\mathrm{CH}_{2}$ group as the number of their gauche interactions to lone pairs rises. The electron population removed from these atoms during the conformational change is gained in the gauche conformers by the oxygen atoms, which results in more negative energy. The electrostatic effects (hard interactions) thus overwhelm the polarizability effect (hyperconjugation: soft interactions) [18]. In the case of acetals with vicinal oxy or other polar substituents, attractive gauche effects [19] might also contribute to the difference in stability of the acetals conformers or/and stereoisomers [20].

Unsubstituted [n,n]-spiroketals have a $C_{2}$ axis - they are chiral. Unsubstituted [n,m]-spiroketals with $\mathrm{n} \neq \mathrm{m}$ are also chiral $\left(\mathrm{C}_{1}\right.$ symmetry). Thus on substituting these systems with one, two, ...substituents X, Y, ... one, two, ...pairs of diastereoisomers can be generated. This is illustrated in Figure 3 for disubstituted spiroketals. Heterolysis of the acetal moiety allows epimerization of the anomeric center but does not racemize these systems. In the case of $\mathbf{4}$, acetal epimerization give 5 whichever C-O bond undergoes heterolysis. 
Figure 3. Epimerization of spiroacetals through acid-catalyzed heterolysis.

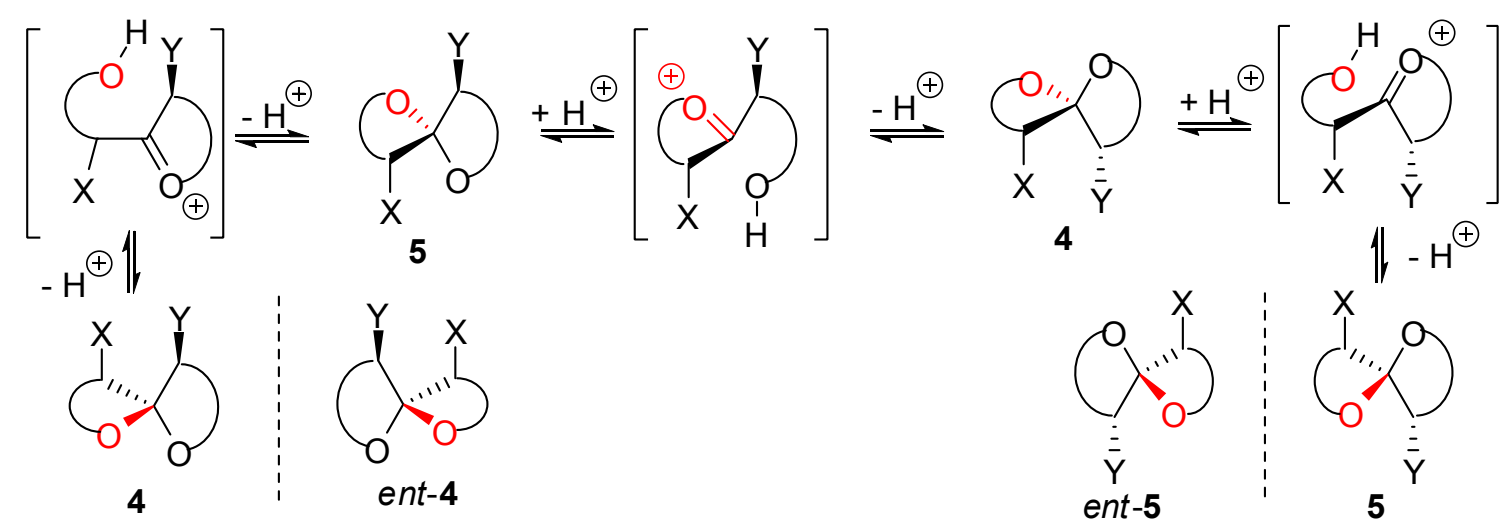

Except for [3,3]-spiroketals that can adopt only one conformation because of the planar oxirane moieties, the other spiroketals with oxetane, tetrahydrofuran and tetrahydropyran rings can generate various conformers (puckering in oxetane [21], twist and envelop conformers for tetrahydrofurans [22], chair and twist boat conformers for tetrahydropyrans [23]) as shown in Figure 4. Depending on the nature of substituents $\mathrm{X}$ and $\mathrm{Y}$, the four possible conformations $(\mathrm{g}, \mathrm{g}),(\mathrm{g}, \mathrm{a}),(\mathrm{a}, \mathrm{g})$ and $(\mathrm{a}, \mathrm{a})$ shown for 4 might have different relative stabilities. Ignoring differential solvation effects, steric factors, gauche effects, electrostatic effects and intramolecular hydrogen bridging due to substituents $\mathrm{X}$ and $\mathrm{Y}$, one expects that $(\mathrm{g}, \mathrm{g})$-conformers are more stable than both $(\mathrm{g}, \mathrm{a})$ - and $(\mathrm{a}, \mathrm{g})$-conformers, themselves expected to be more stable than the corresponding (a,a)-conformers for stereoelectronic reasons (see above). In the cases of [5,6]- and [6,6]-spiroketals, the tetrahydropyran ring usually prefers chair conformations. Their interconversions are not degenerate upon substitution as equatorial substituents in one chair occupy axial positions (destabilizing gauche interactions) in the other. This might affect stability difference between $(\mathrm{g}, \mathrm{g}),(\mathrm{g}, \mathrm{a}),(\mathrm{a}, \mathrm{g})$ and $(\mathrm{a}, \mathrm{a})$-conformers and favor one of the two possible diastereoisomeric spiroketals (4 vs 5), should they equilibrate by acetal epimerization (Figure 3). If substituents $\mathrm{X}$ and $\mathrm{Y}$ are part of a bridge in a tricyclic structure, any of the $(\mathrm{g}, \mathrm{g}),(\mathrm{g}, \mathrm{a}),(\mathrm{a}, \mathrm{a})$ or $(\mathrm{a}, \mathrm{a})$ conformations might be obtained by the adequate choice of the nature of the bridge and relative configuration of the substituted centers. Such bridging might also favor other conformations than chairs for their tetrahydropyran moieties.

Figure 4. Possible conformers for diastereoisomeric [n,m]-spiroketals (n,m > 3).

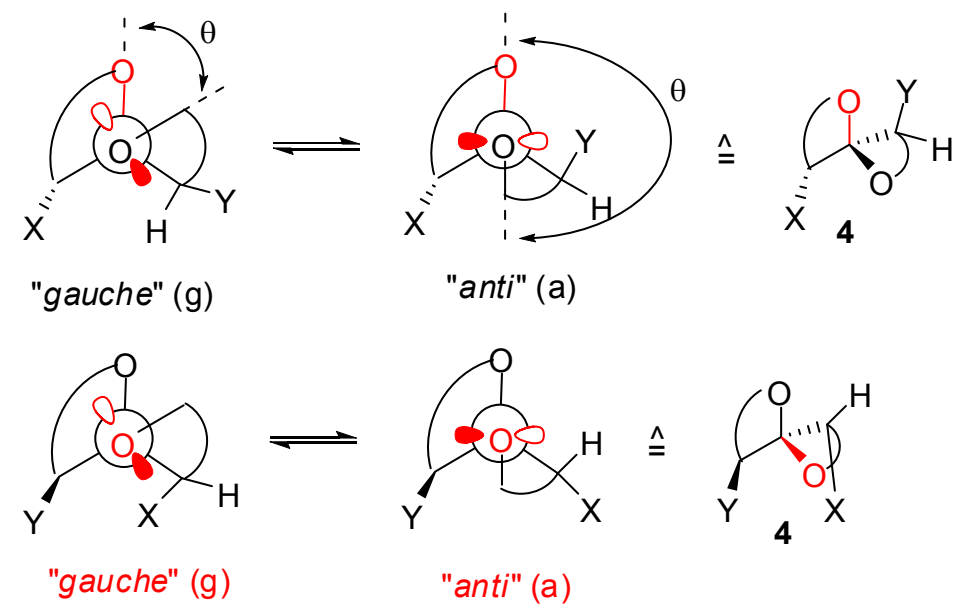


Most natural products containing spiroketal subunits display five and six membered rings. The pioneering synthetic efforts devoted to the preparation of such structures assumed that the configuration of the spiro carbon in natural compounds corresponds to the most stable (g,g)conformation. In fact, several naturally occurring spiroketals adopt other conformations. This review covers the recent synthetic approaches to naturally occurring non-anomeric [6,6]- and [6,5]-spiroketals with particular focus on the spiroketal fragments of spongistatins/altohyrtins.

\section{Synthesis of naturally occurring $[6,6]$-spiroketals}

\subsection{AB and CD spiroketals of spongistatins/altohyrtins}

In 1993, the research groups of Pettit, Kitagawa/Kobayashi and Fusetani independently reported the isolation, from marine sponges, of a family of related highly oxygenated macrolactones containing highly substituted 6,6-spiroketals and tetrahydropyran rings [24]. These molecules were found to be among the most potent cancer cells growth inhibitors tested to date by the U.S. National Cancer Institute on a panel of 60 human carcinoma cell lines, with $\mathrm{GI}_{50}$ values in the nanomolar and picomolar ranges. Despite these promising properties, further biological investigations were precluded by the extremely low quantities that can be obtained by extraction of marine organisms and the unacceptable ecological impact of larger scale isolation of the producing sponges. This scarce abundance, combined with remarkable structural complexity, prompted many research groups to address the challenge of the synthesis of these macrolides. The structure of these appealing molecules is based on a 42-membered macrolactone embedded with two spiroketal subunits (AB and $C D$ ) and two highly substituted tetrahydropyrans ( $\mathrm{E}$ and $\mathrm{F}$ ), and functionalized by a sensitive trienic side chain, for a total of 24 stereocenters. Spongistatins 5, 7-9 contain an additional 5 membered ring within the skeleton. Interestingly, while the $\mathrm{AB}$ spiroketal adopt a $(\mathrm{g}, \mathrm{g})$-conformation, the $\mathrm{CD}$ spiroketal stands in a $(\mathrm{g}, \mathrm{a})$ conformation. It probably gains some stabilization from intramolecular hydrogen bonding. The routes developed, after 2004, toward the obtention of the (g,a)-CD subunit $v s$ the (g,g)-AB subunit of these macrolides will be detailed.

After a first report on the total synthesis of spongistatin 1/altohyrtin A in 2001 [25], the Paterson group disclosed more recently a detailed account of their studies on this target [26]. Approach to the

$\mathrm{C}_{1}-\mathrm{C}_{15} \mathrm{AB}$ spiroketal subunit was based on acid-catalyzed acetal formation from a linear precursor to deliver the thermodynamically favored isomer (Scheme 1) [26a]. The dihydroxy ketone precursor 8 arose from addition of the boron enolate from methyl ketone 6 to aldehyde 7, thus installing the 5,9anti relationship of the alcohols. Selective removal of the triethylsilyl groups in the presence of PPTS induced spirocyclization to the unique thermodynamically favoured spiroketal $\mathbf{9}$. This intermediate was, in turn, efficiently transformed into the fully elaborated $A B$ fragment of spongistatin 1/altohyrtin A. 
Scheme 1. Synthesis of the AB spiroketal subunit of spongistatin1 by Paterson et al.

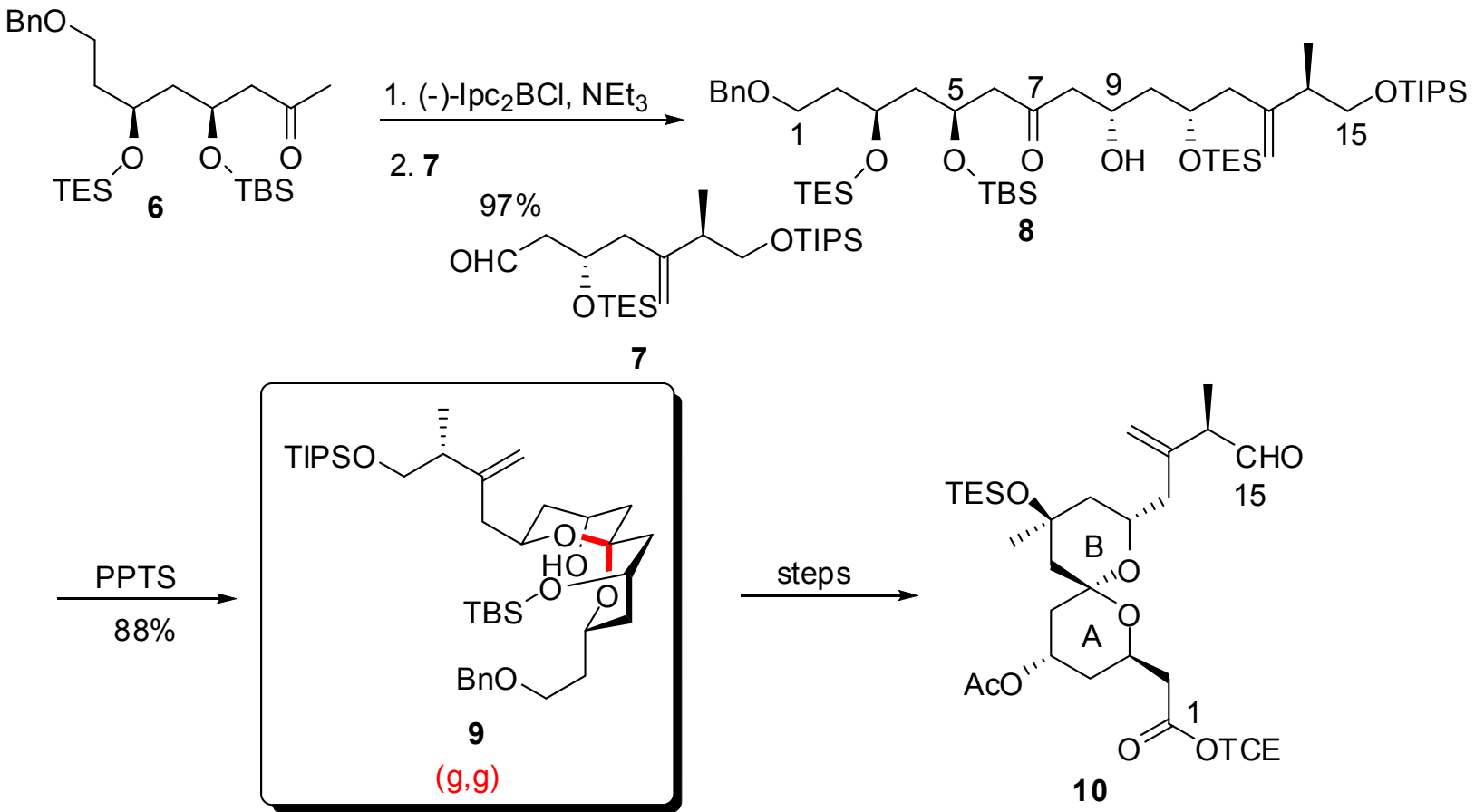

For the synthesis of the CD fragment, a stepwise construction of both rings was envisaged through a kinetically-controlled intramolecular hetero-Michael addition on a D-ring dihydropyrone precursor (Scheme 2) [26b].

Scheme 2. Kinetically-controlled synthesis of the CD spiroketal of spongistatin 1 according to Paterson et al.
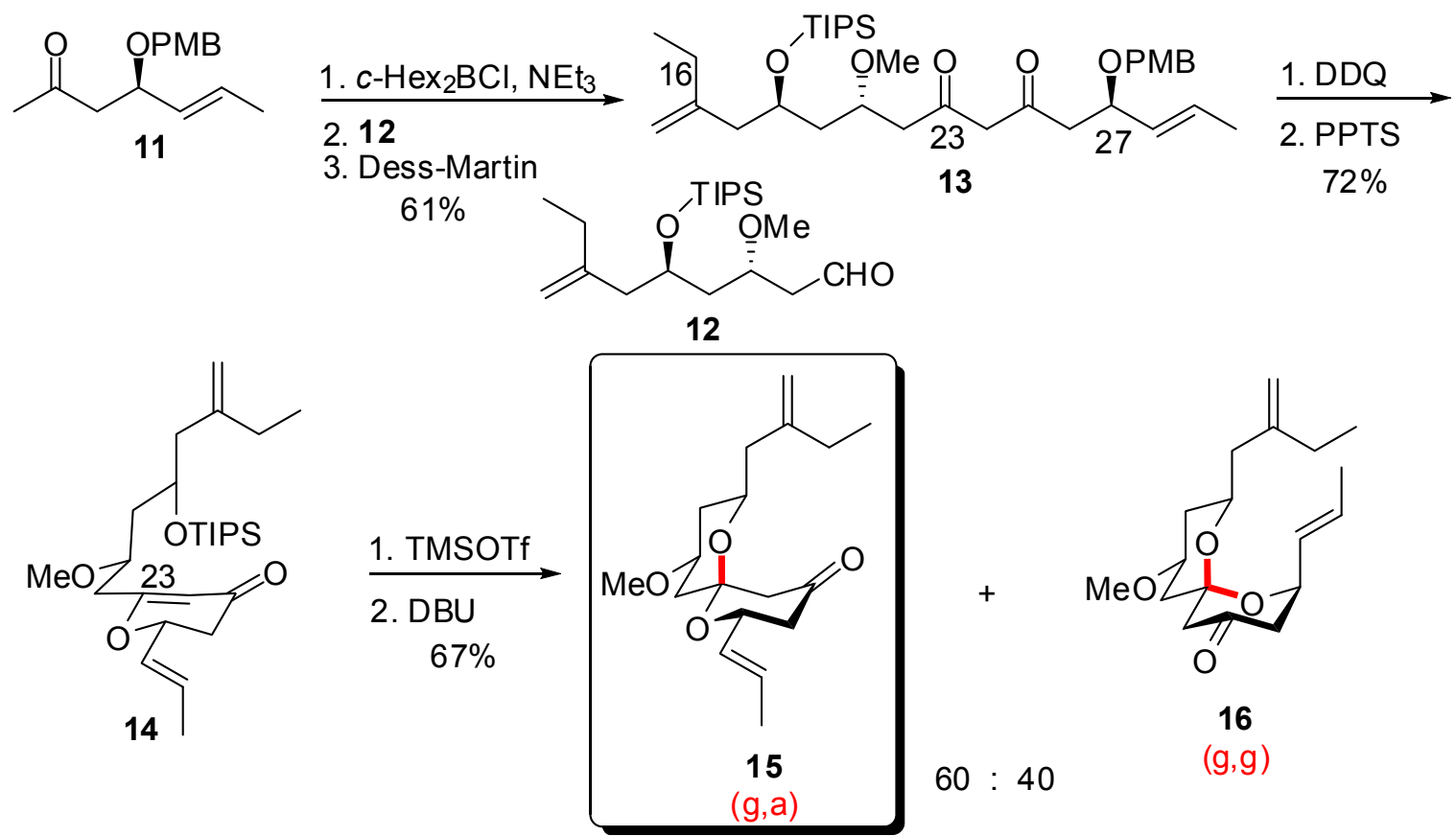
Stereoselective boron aldol coupling to aldehyde $\mathbf{1 2}$ and subsequent oxidation of the intermediate aldol at $\mathrm{C}(23)$ provided the precursor of ring D. Removal of the PMB ether, followed by dehydrative cyclization afforded dihydropyranone $\mathbf{1 4}$ in good yield. Desilylation allowed intramolecular heteroMichael addition on enone at $\mathrm{C}(23)$ position, under mild basic conditions. Nevertheless, the desired, less stable, (g,a)-spiroketal 15 was obtained with modest selectivity, along with the undesired $(\mathrm{g}, \mathrm{g})$ spiroketal 16.

The same group reported another route to the CD spiroketal of spongistatin 1, through thermodynamic control [26b]. Aldol condensation of boron enolate derived from methyl ketone 17 to aldehyde 18 ensured the anti relationship of hydroxyls at $\mathrm{C}(21)$ and $\mathrm{C}(25)$. Acidic cleavage of silyl ethers led to spirocyclization to provide a 1:5 mixture of the desired (g,a)-spiroketal 21 and the undesired thermodynamically favoured $(\mathrm{g}, \mathrm{g})$-isomer 20. Several cycles of equilibration assisted by hydrogen bonding / separation provided larger quantities of the desired spiroketal, up to 69\% yield. Separation of the two isomers by gradient elution column chromatography delivered gram scale quantity of the (g,a)-spiroketal 21. Further functionalization generated the CD spiroketal 22 of spongistatin 1 .

Scheme 3. Synthesis of the CD spiroketal of spongistatin 1 under thermodynamic control according to Paterson et al.<smiles>CO[C@H](CC(C)=O)C[C@@H](C)C/C=C\[Sb]</smiles>

17

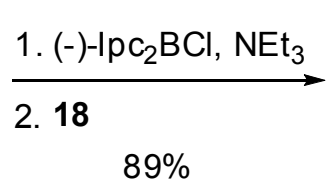

$89 \%$

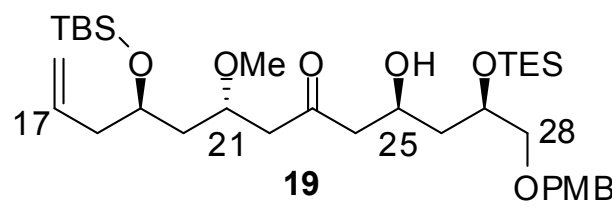<smiles>[R16]OC[C@@H]([O-])CC=O</smiles>
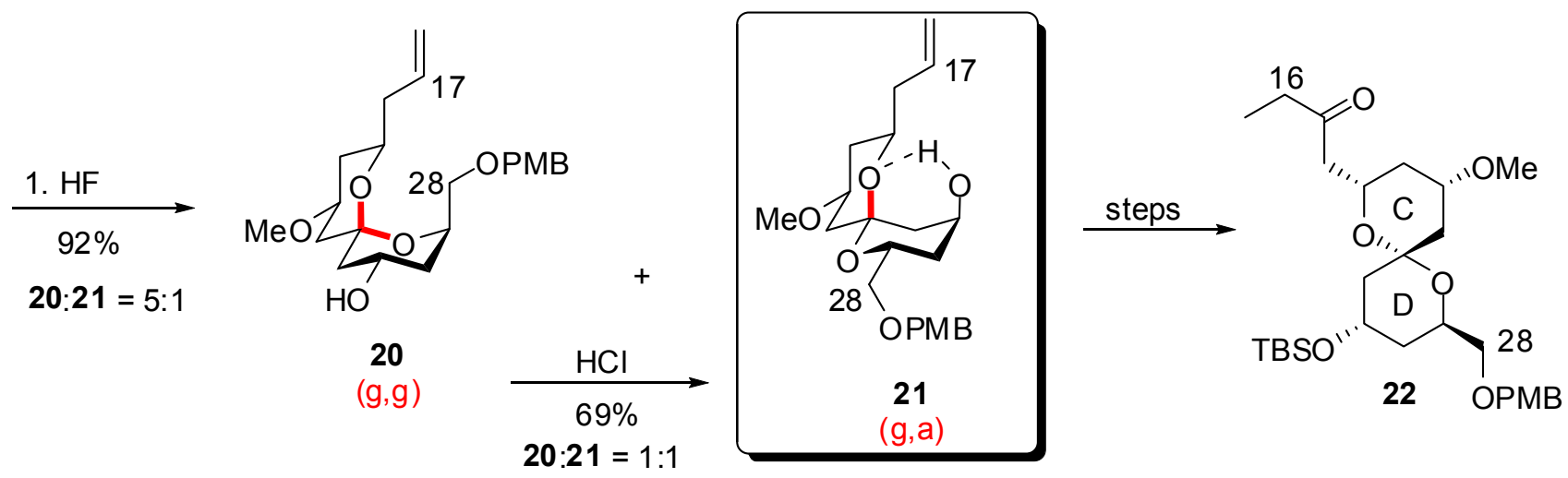

While both approaches generated a mixture of spiroacetal epimers, the second route using thermodynamically controlled spirocyclization followed by acid-catalyzed equilibration was practically more useful due to easier separation of spiroketals $\mathbf{2 0}$ and $\mathbf{2 1 .}$

Guided by the latent $C_{2}$ pseudo-symmetry of spongistatin 1 about the $\mathrm{C}(15)$ atom, Ley and coworkers designed a synthetic pathway where both $\mathrm{AB}$ and $\mathrm{CD}$ spiroketals derive from a common linear precursor [27]. For that purpose, addition of the acetylide anion of a 1:1 C(5) epimeric mixture 24 to aldehyde 23, followed by oxidation of the intermediate alcohol led to ynone 25 (Scheme 4). Double conjugate addition of 1,3-propanedithiol and subsequent acidic treatment provided a 1:0.7:0.26 mixture of three spiroketals $(\mathbf{2 7}, \mathbf{2 8}, \mathbf{2 9})$ presenting the AB (g,g)-, CD (g,g)- and CD (g,a)- 
arrangements, respectively. Successive equilibration protocols in the presence of $\mathrm{Ca}^{2+} /$ perchloric acid efficiently converted the undesired $(\mathrm{g}, \mathrm{g})$ spiroketal 28 into its $(\mathrm{g}, \mathrm{a})$ isomer 29. These intermediates were then converted into fully elaborated $\mathrm{AB}$ and $\mathrm{CD}$ spiroketals of spongistatin 1 (30, 31). Interestingly, this methodology took advantage of the latent $C_{2}$ pseudo-symmetry of spongistatin 1 about the $\mathrm{C}(15)$ atom to give a rapid access to both $\mathrm{AB}$ and $\mathrm{CD}$ spiroketals from the same linear precursor. Furthermore, in the scale-up synthesis of spongistatin 1, the same group reported a highly efficient azeotropic reflux chromatography to separate the isomeric spiroketals 27-29 [28].

Scheme 4. Synthesis of AB and CD spiroketals of spongistatin 1 according to Ley et al.

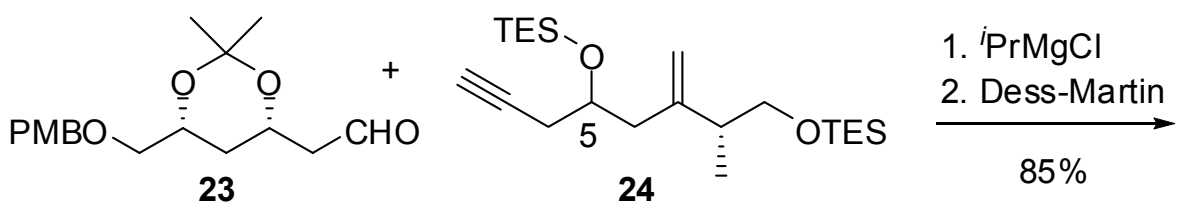

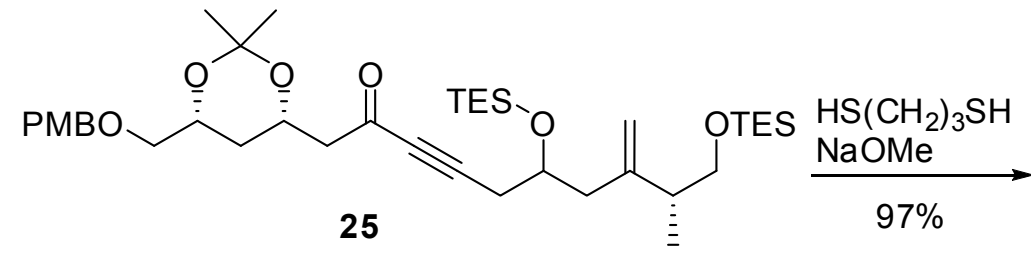

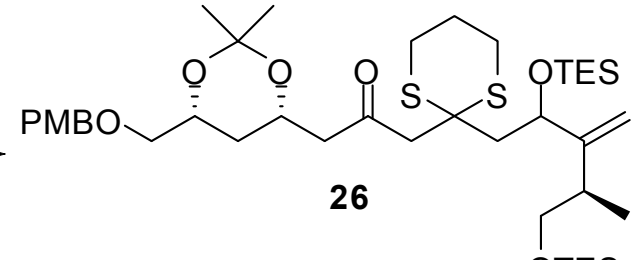
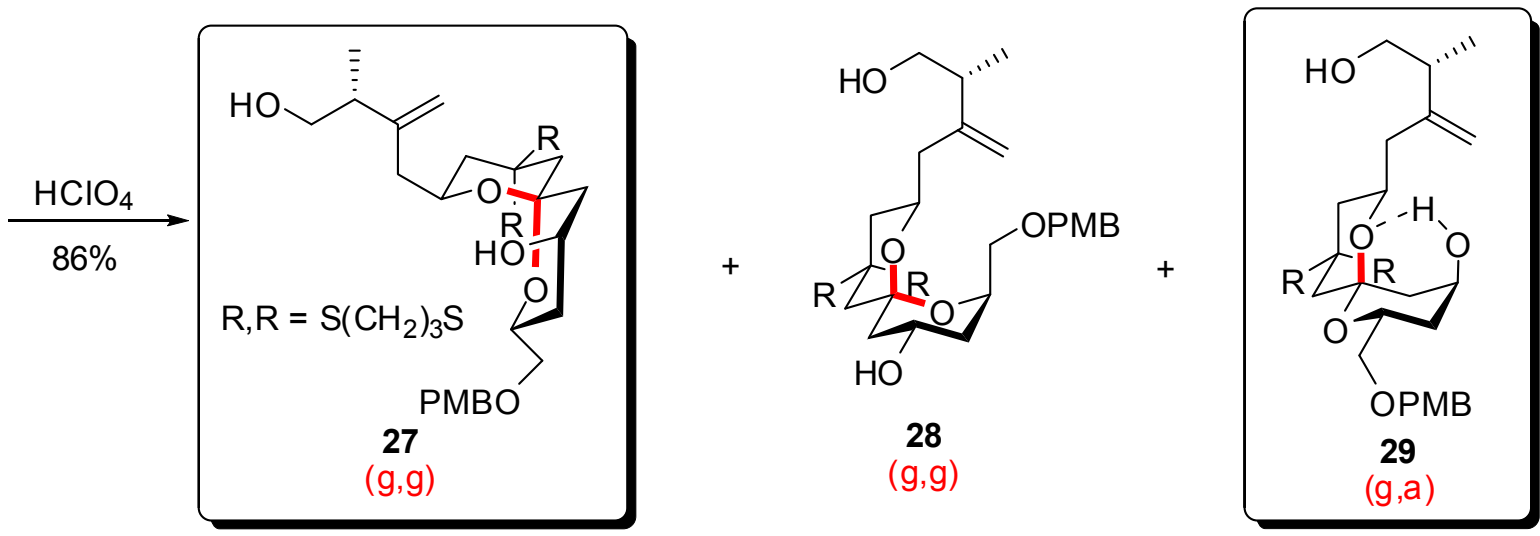

$27: 28: 29=1: 0.74: 0.26$

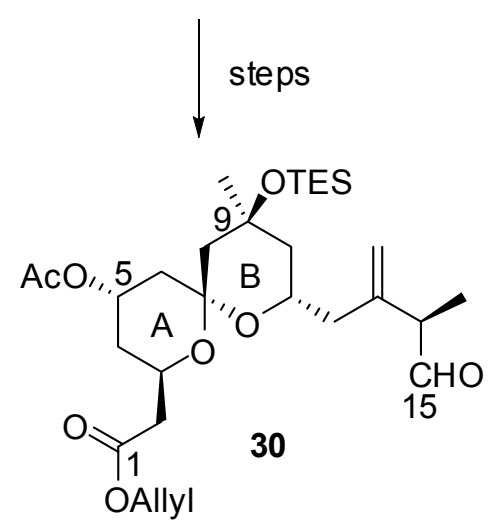

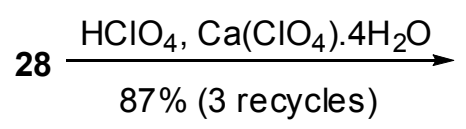

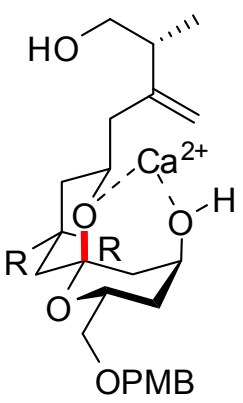

29, calcium complex<smiles>CC[Te](=O)C[C@H]1C[C@@H](OC)C[C@@]2(C[C@@H](O[13CH3])C[C@H](COC(C)(C)C)O2)O1</smiles> 
Based on the methodology previously developed for the asymmetric synthesis of $\mathrm{C}_{15}$ polyketides from readily available 2,2'-methylene difuran, Vogel et al. disclosed an efficient pathway to an advanced precursor of the AB spiroketal of spongistatins, and analogues (Scheme 5) [29]. Functionalization of the enantiomerically enriched diol 32 led to semi-opened polyol 33. Further orthogonal protecting group manipulations led to the key intermediate olefin 34. A sequence of ozonolysis / reductive treatment afforded hemiketal 35 in high yield. Acidic treatment with CSA allowed spirocyclization to the thermodynamic $(\mathrm{g}, \mathrm{g})$-spiroketal 36 which was further transformed into and advanced precursor of the AB spiroketal of spongistatins 38. Interestingly, when $\mathbf{3 5}$ was submitted to PPTS, the cyclization process afforded a mixture of the non-anomeric spiroketal $37((\mathrm{a}, \mathrm{a})$-isomer $)$ and the thermodynamic stereoisomer 36 in a 2:3 ratio. Variation on the nature of the acidic partner can therefore lead to different stereoisomeric 6,6-spiroketal from the same precursor.

Scheme 5. Synthesis of an advanced precursor of the AB spiroketal of spongistatins according to Vogel et al.

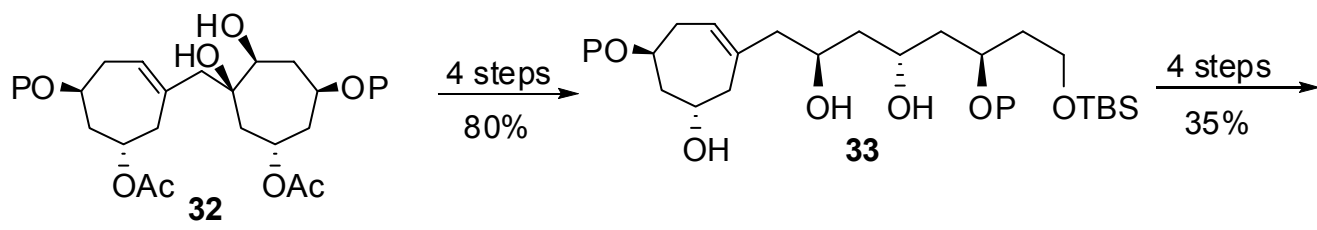

$98.4 \%$ ee, $\mathrm{P}=\mathrm{PMBz}$

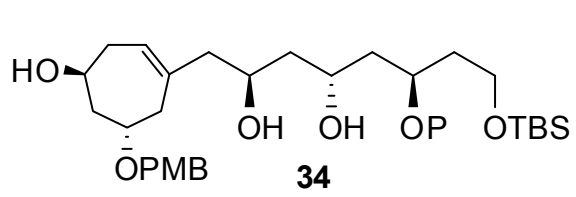

1. $\mathrm{O}_{3}, \mathrm{CH}_{2} \mathrm{Cl}_{2},-78{ }^{\circ} \mathrm{C}$
2. $\left(\mathrm{CH}_{3}\right)_{2} \mathrm{~S},-78{ }^{\circ} \mathrm{C}$
$\stackrel{3}{\longrightarrow}$

3. K-selectride, THF

$82 \%$

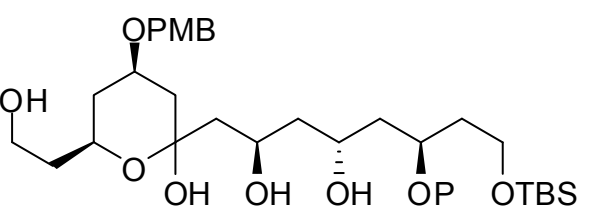

35

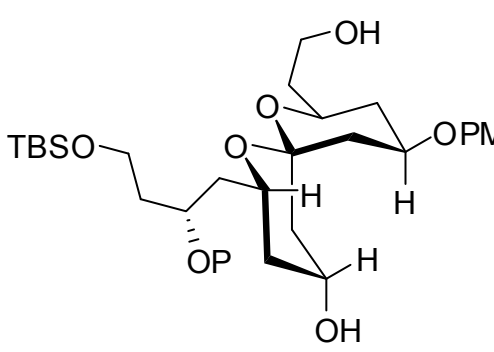

37

$(\mathrm{a}, \mathrm{a})$

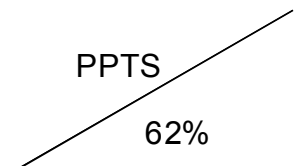

$88 \% \begin{aligned} & \text { CSA cat } \\ & \text { PhMe }\end{aligned}$

$+\quad 30$

$37: 36=2: 3$

(separable)

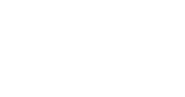

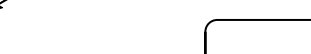

$\mathrm{HO}$

$\mathrm{PMBO}$

38
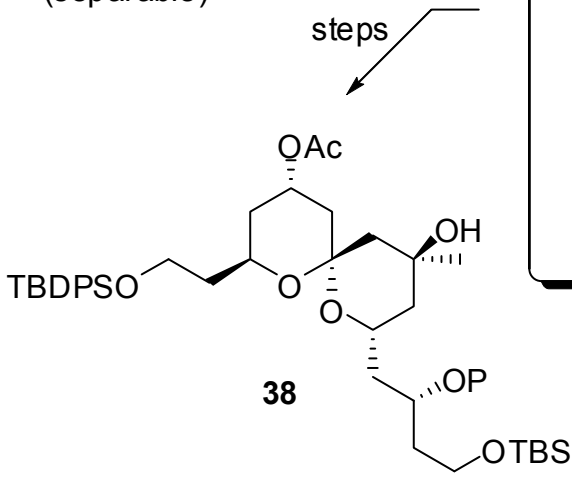

Following another approach based on the simultaneous functionalization of diolefin 39, the same authors reported a sequence of ozonolysis / reductive treatment to afford bis-hemiketal $\mathbf{4 0}$ (Scheme 6) [30]. Subsequent acidic treatment, first with aqueous HF and then with CSA, induced spirocyclization to the tricyclic intermediate $\mathbf{4 1}$, in high yield. 
Scheme 6. Synthesis of tricyclic spiroketals according to Vogel et al.

$\mathrm{BOMO}$

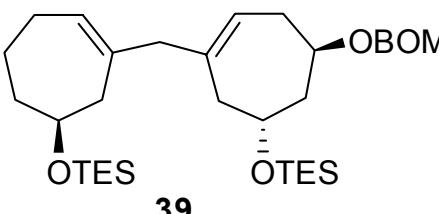

39

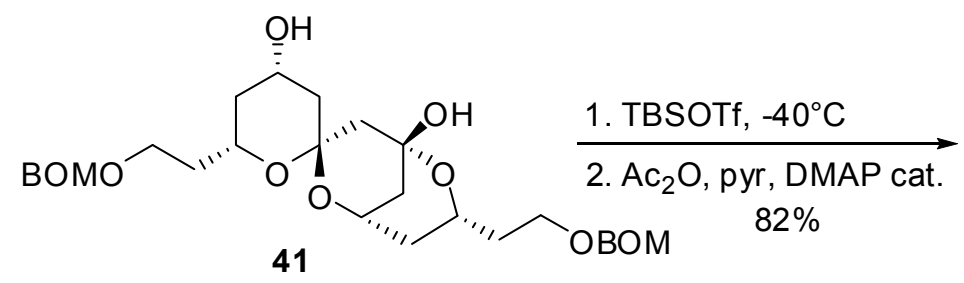

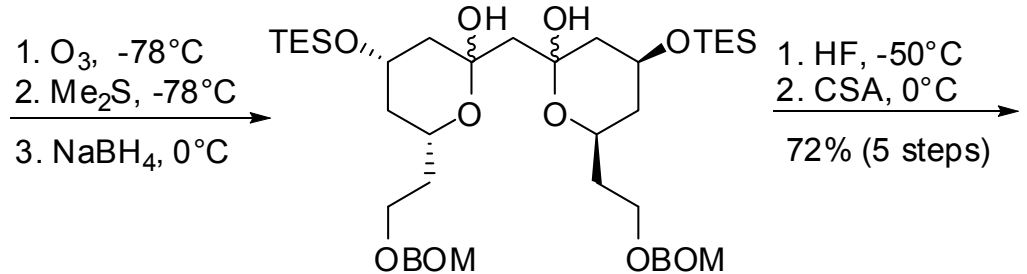

40

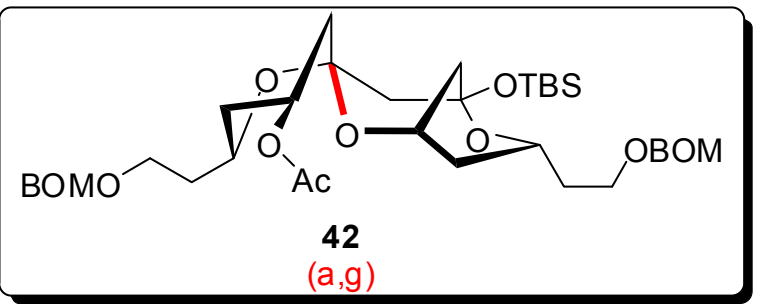

The formation of a tricyclic structure allowed trapping of the kinetic $(\mathrm{a}, \mathrm{g})$-spiroketal (one axial C-O bond for the $[6,6]$-spiroketal unit) as demonstrated by 2D-NMR experiments on the orthogonally protected derivative $\mathbf{4 2}$.

\subsection{Synthesis of other nonanomeric [6,6]-spiroketals related to natural products}

In order to access spiroketals that do not adopt $(\mathrm{g}, \mathrm{g})$-conformation (with two axial $\mathrm{C}-\mathrm{O}$ bonds for their spiroketal moieties), several kinetic spirocyclization reactions have been developed. Mild nonacidic conditions, involving reduction of an ynone precursor, have been reported by Koutek et al. (Scheme 7) [31]. Hydrogenation of derivative $\mathbf{4 3}$ induced both reduction of the triple bond and hydrogenolysis of the benzyl ether to afford a mixture of isomeric spiroketals from which the "nonanomeric" derivatives 45 (axial/equatorial C-O bonds) and 46 (equatorial/equatorial C-O bonds) were predominant.

Scheme 7. Access to thermodynamically non stabilized $[6,6]$-spiroketals according to Koutek et al.

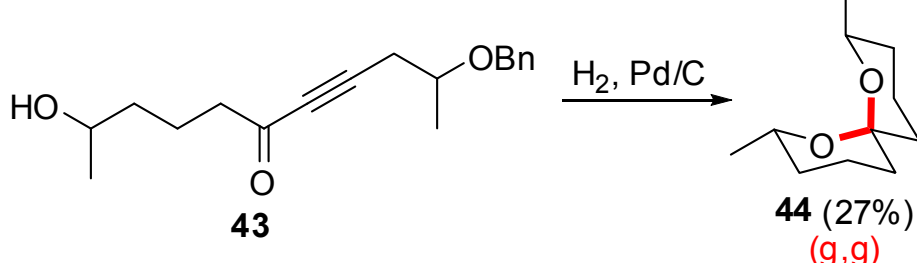

$(g, g)$

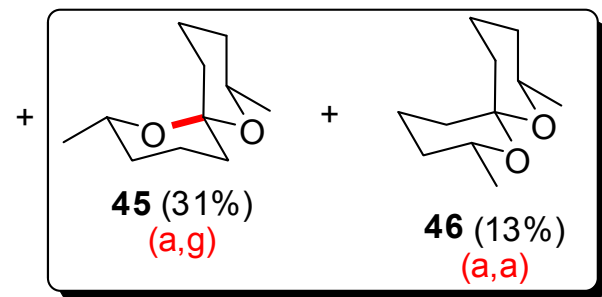

Spirocyclization reactions from carbohydrate-derived precursors were also explored to access nonthermodynamic spiroketals. The group of Goekjian [32] prepared the exo-glycal derivative 49 through a modified Julia olefination on carbohydrate lactone 47 (Scheme 8). Treatment under kinetic conditions resulted in an initial 3.3:1 selectivity in favor of the (a,g)-spiroketal 50. In contrast, the $(\mathrm{g}, \mathrm{g})$-isomer 51 was obtained in the presence of $\mathrm{p}$-toluene sulfonic acid. 
Scheme 8. Access to "non-anomeric" spiroketals from carbohydrate derived precursors according to Goekjian et al.

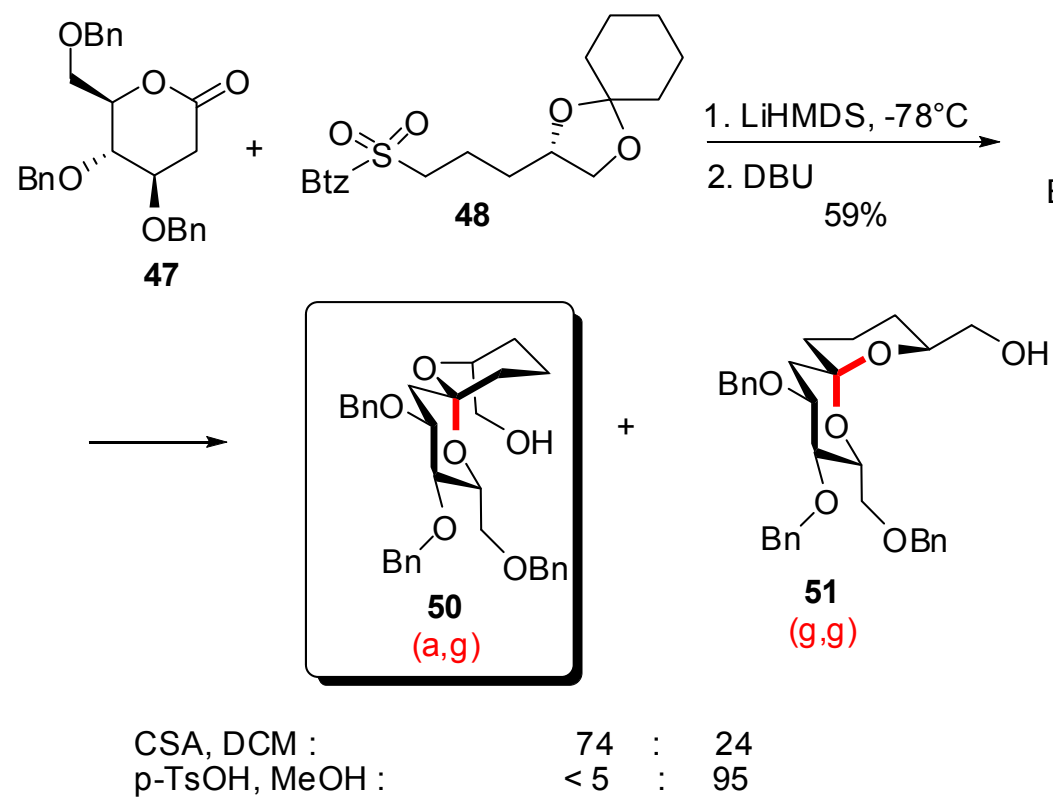

A carbohydrate template was also disclosed by Quayle et al. [33] for the preparation of unsaturated spiroketals related to the milbemycins / avermectins family (Scheme 9).

Scheme 9. Carbohydrate-based synthesis of spiroketals according to Quayle et al.
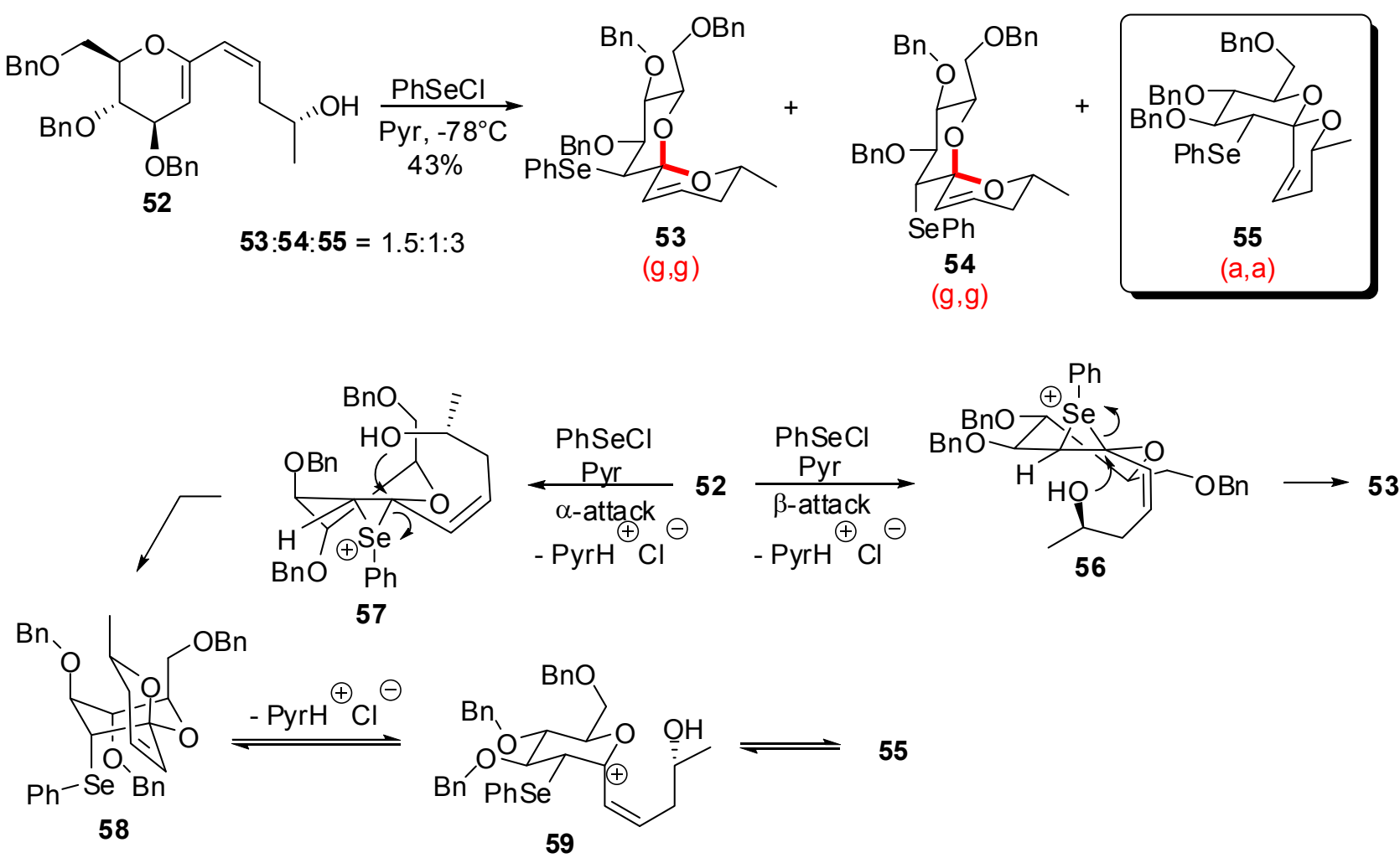

Exposure of dienol $\mathbf{5 2}$ to $\mathrm{PhSeCl}$ in basic medium promoted cyclization under kinetic control to deliver a mixture of spiroketals 53-55, enriched in the non-anomeric (a,a)-isomer 55. The major products probably arose from the trans-diaxial opening of kinetic epi-selenonium intermediates $\mathbf{5 6}$ and 
57. Formation of $\mathbf{5 5}$ would arise from intermediate $\mathbf{5 8}$ that undergoes facile isomerization via an allylic glycosyl cation intermediate $\mathbf{5 9}$.

Kinetic spirocyclization reactions were also disclosed by Tan et al. [34] through the sterocontrolled opening of glycal epoxides (Scheme 10). Treatment of epoxy-glycal 60 in the presence of $\mathrm{MeOH}$ at low temperature, induced equatorial installation of the oxygen nucleophile to deliver the (g,a)spiroketal 61 with complete stereoselectivity and high yield. The authors suggested that the reaction proceeded through $\mathrm{MeOH}$ hydrogen bonding catalysis. The corresponding (g,g)-spiroketal 62 was isolated in excellent yield after subjection of the same starting epoxide to acidic conditions. The same research group similarly explored the reactivity of stereoisomeric glycal epoxides such as 64, formed in situ by epoxidation of erythro-glycal 63 [35]. Treatment of the nascent epoxide with multidentate Lewis acids, in particular $\mathrm{Ti}\left(\mathrm{O}^{i} \mathrm{Pr}\right)_{4}$, induced spirocyclization with retention of configuration at $\mathrm{C}(1)$ to produce the (g,a)-spiroketal $\mathbf{6 5}$, through a metal chelated early transition state. These methodologies were extended to other related glycal epoxides, thus giving access to stereochemically diversified spiroketals.

Scheme 10. Spirocyclizations from glycal epoxides according to Tan et al.

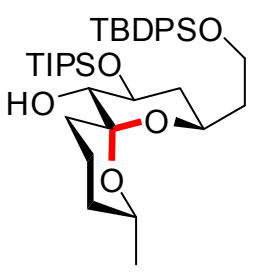

62

$(\mathrm{g}, \mathrm{g})$

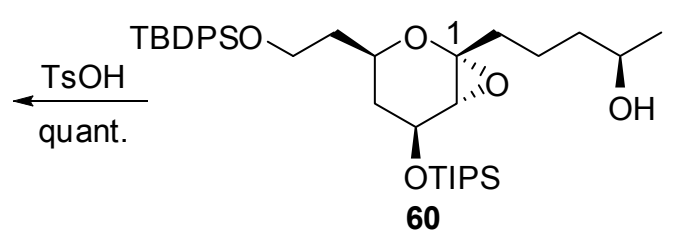

60
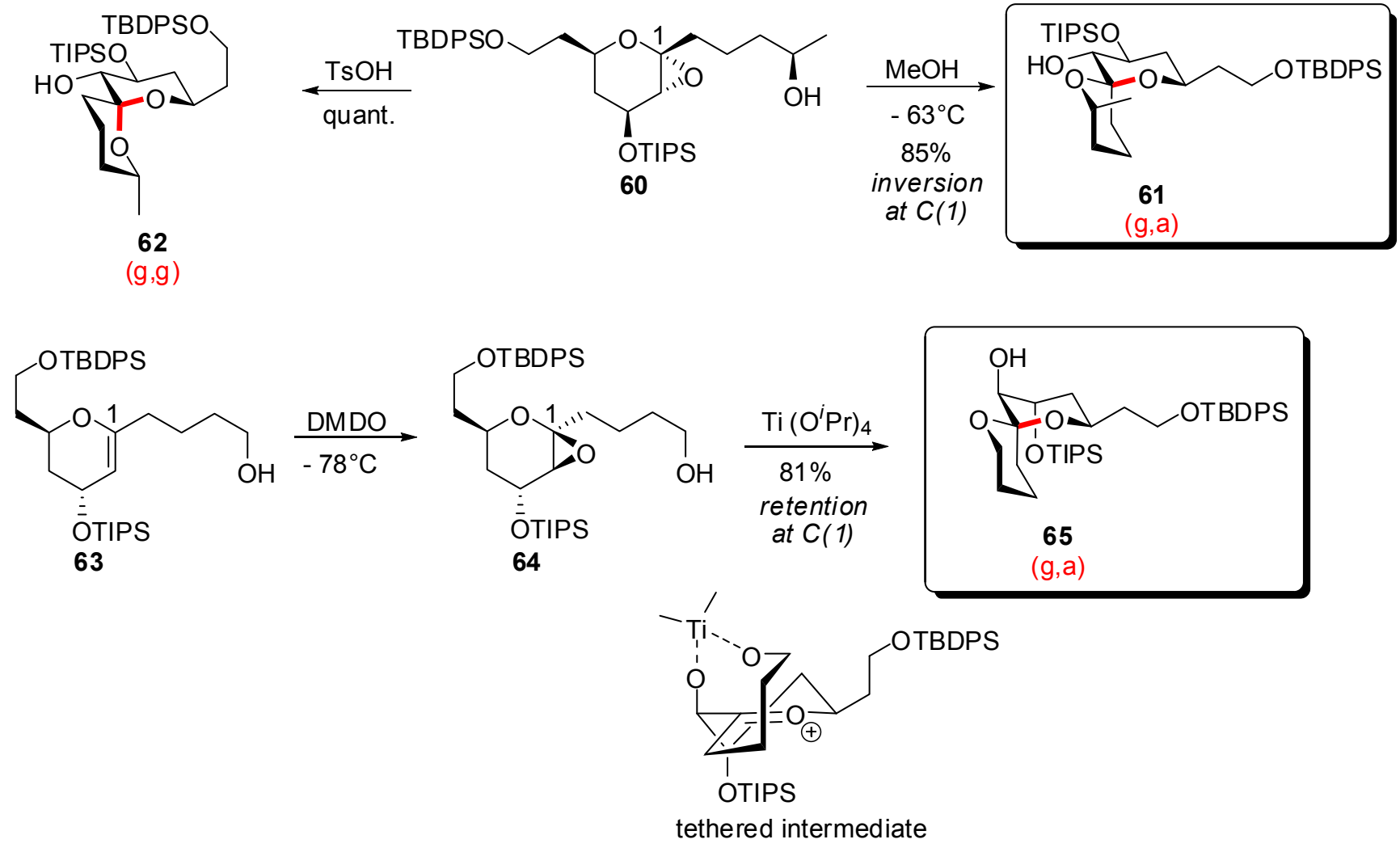

Fuwa and Sasaki reported the use of endocyclic enol ethers in kinetically controlled spirocyclizations to access both anomeric and non-anomeric spiroketals (Scheme 11) [36]. The precursor enol ethers were synthesized through a Suzuki-Miyaura coupling / ring closing metathesis sequence from enol phosphates of type 66. Depending on the local structure of the enol ether (configuration of the alcohol moiety), iodospirocyclization led either to the anomeric (g,g)-spiroketal 71 or to the non-anomeric $(\mathrm{a}, \mathrm{g})$-spiroketal 72, with high stereoselectivities. 
Scheme 11. Synthesis of spiroketals from endocyclic enol ethers according to Fuwa and Sasaki.<smiles>C=C[C@H](C[C@@H](Cc1ccccc1)OCc1ccccc1)OC(C)(C)C</smiles>

66
1. 9-BBN-H

then $\mathrm{Pd}\left(\mathrm{PPh}_{3}\right)_{4}$ cat.

$\mathrm{Cs}_{2} \mathrm{CO}_{3}, 50^{\circ} \mathrm{C}$

2. Grubbs II cat, $70^{\circ} \mathrm{C}$

67, $X=$ OTBS, $Y=H$

68, $X=H, Y=$ OTBS<smiles>[Y10]OCC([Y])([X])CCCC1=C[C@@H](Br)CC(COCc2ccccc2)O1</smiles>

69, $X=$ OTBS, $Y=H(56 \%)$

70, $X=H, Y=$ OTBS $(64 \%)$

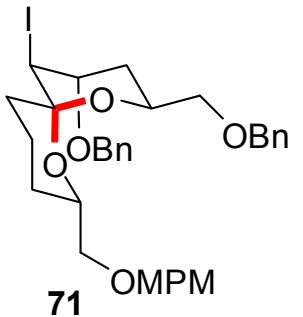

$(g, g)$

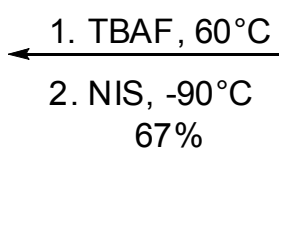

$6970 \frac{\text { 1. TBAF }, 60^{\circ} \mathrm{C}}{\longrightarrow}$

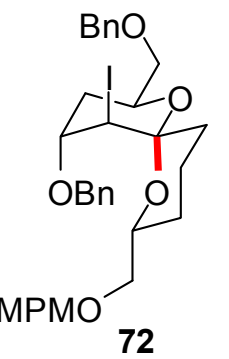

$(\mathrm{g}, \mathrm{a})$

Several reports also indicated the use of an initial mixture of both anomeric (g,g)- and nonanomeric (a,g)- or (g,a)-spiroketals to access stereochemically related natural products from a common precursor. In their synthetic studies toward the antifungal antibiotics spirofungins, Shimizu et al [37] proposed a spiroketalization process induced by PPTS on alkynyl methyl ketal $\mathbf{7 3}$ to produce a mixture of epimeric spiroketals 74 (Scheme 12).

Scheme 12. Synthesis of the spiroketals of Spirofungins A and B according to Shimizu et al.<smiles>CC#CC[C@H](O)[C@H](C)CC[C@@H]1CC[C@@H](C)[C@@H](CO[R6](C)(C)C)O1</smiles><smiles>CC(I)=CCC1CC2CCC(CCO)(OCCCO)OC1C2</smiles><smiles>CC(I)=CCC1CC2CC(CO)CC(CC1C)O2</smiles><smiles>CC[18OH]</smiles>

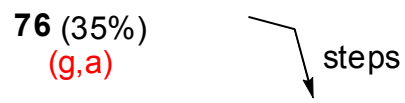<smiles>CC(/C=C/C(O)C(C)/C=C/C(=O)O)=C\C[C@H]1O[C@@]2(CC[C@H](C)[C@@H](/C=C/C(C)=C/C(=O)O)O2)CC[C@@H]1C</smiles><smiles>CC(/C=C/C(O)C(C)/C=C/C(=O)O)=C\C[C@H]1O[C@@]2(CC[C@H](C)[C@@H](/C=C/C(C)=C/C(=O)O)O2)CC[C@H]1C</smiles>

Functionalization of the triple bond and removal of the silyl ether allowed separation of the (g,g)spiroketal 75 and the (g,a)-stereoisomer 76 in 40 and 35\% yield, respectively. These two intermediates were engaged in the same synthetic sequence to deliver spirofungin A and spirofungin B in good 
overall yields. The stereochemically related pteridic acids A and B were also prepared from a common precursor by Paterson et al. [38]. Smooth silyl ether cleavage on enone $\mathbf{7 0}$ afforded a roughly equimolar mixture of spiroketals $\mathbf{7 1}$ and $\mathbf{7 2}$ presenting axial / axial and axial / equatorial configurations, respectively. Separation of these isomers provided access to pteridic acids A and B through a common synthetic sequence.

Scheme 13. Synthesis of the spiroketals of pteridic acids A and B according to Paterson et al.

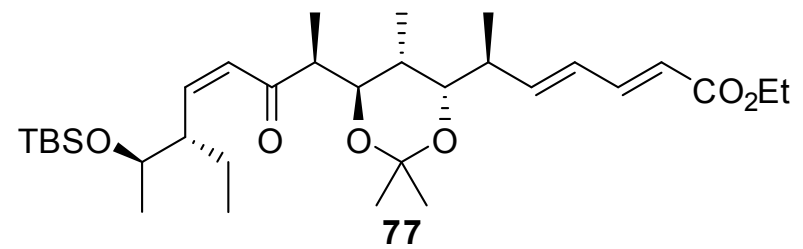

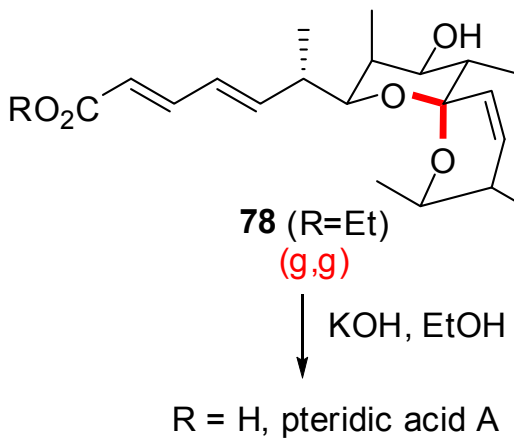

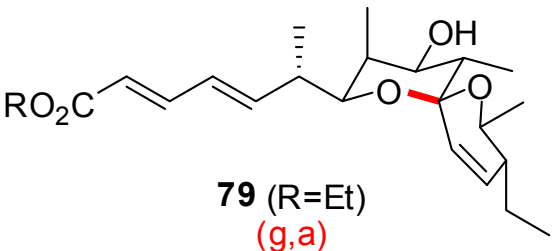
$(\mathrm{g}, \mathrm{a})$

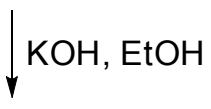
$\mathrm{R}=\mathrm{H}$, pteridic acid $\mathrm{B}$

Scheme 14. Synthesis of the spiroketals of pteridic acids A and B according to Kuwahara et al.

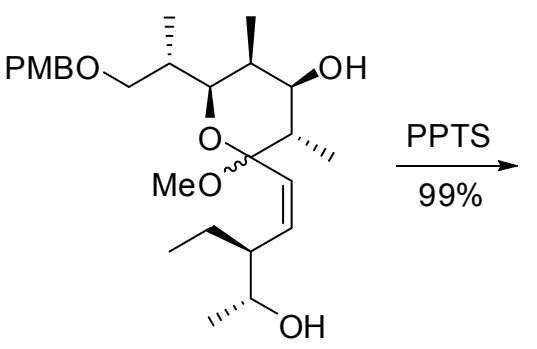

80

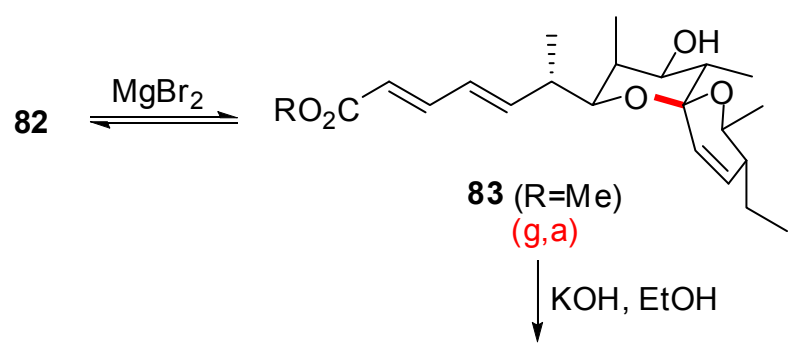

$\mathrm{R}=\mathrm{H}$, pteridic acid $\mathrm{B}$

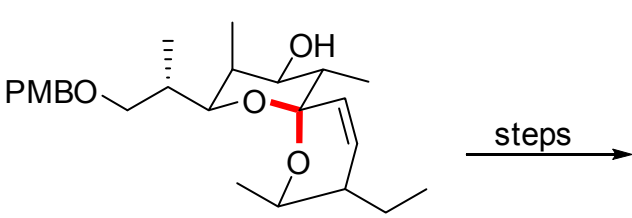

$81(\mathrm{R}=\mathrm{Et})$

$(g, g)$

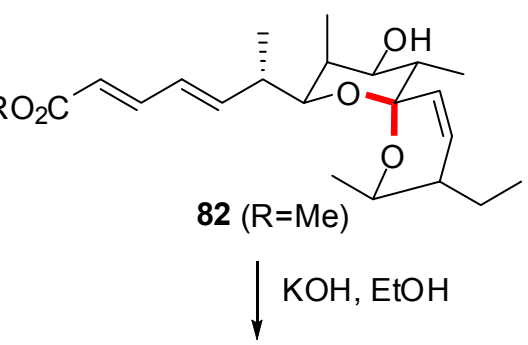

$\mathrm{R}=\mathrm{H}$, pteridic acid $\mathrm{A}$

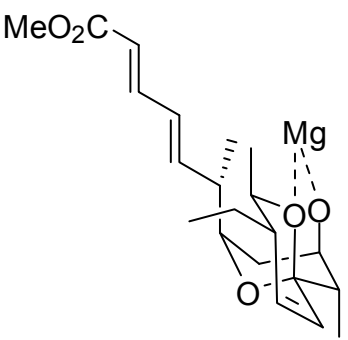

intermediate magnesium chelate (84)

Another approach to pteridic acids A and B was proposed by Kuwahara et al. (Scheme 14) [39]. The (g,g)-spiroketal of pteridic acid A was obtained through acidic treatment of the methyl ketal precursor 80, resulting in the selective formation of the $(\mathrm{g}, \mathrm{g})$-isomer. Subsequent transformation 
provided methyl ester $\mathbf{8 2}$ as the direct precursor of pteridic acid A. Lewis acid catalyzed epimerization of 82 allowed the isolation of the anomerically disfavored spiroketal $\mathbf{8 3}$ in $40 \%$ yield, through the magnesium chelate intermediate $\mathbf{8 4}$. A final hydrolysis led to pteridic acid B.

\section{Synthesis of naturally occurring nonanomeric [6,5]-spiroketals}

While [6,6]-spiroketal systems are the most common nonanomeric spiroketals in natural products, the nonanomeric [6,5]-spiroketal core is also present in many natural products of biological interest and thus lead to important synthetic efforts.

Rychnovsky and co-workers took advantage of their methodology developed for the synthesis of non-anomeric [5,6] and [6,6]-spiroketals [40] to the synthesis of the AB-spiroketal of Pectenotoxin 2 [41] and to Attenol A [42]. By reversing the usual roles of electrophile and nucleophile in the synthesis of spiroketals, the preferred anomeric isomer was efficiently suppressed. Treatment of cyanoacetal $\mathbf{X}$ by lithium di-tert-butylbiphenylide (LiDBB) furnished, through single electron transfer and after the loss of the cyanide anion, the anomeric radical $\mathbf{Y}$ (Scheme 15) [43]. When the second electron was added during the reduction, the resulting alkyl lithium species $\mathbf{Z}$ remained locked in the axial position [44]. If the electrophilic substitution occured with retention of configuration, the (a,g)-spiroketal was generated. Competitive pathways, reaction of the equatorial alkyllithium species $\mathbf{Z}$ ' or inversion during the substitution of $\mathbf{Z}$ ', explained the formation of the minor $(\mathrm{g}, \mathrm{g})$-epimer.

Scheme 15. Mechanism of cyclization according to Rychnovsky et al.

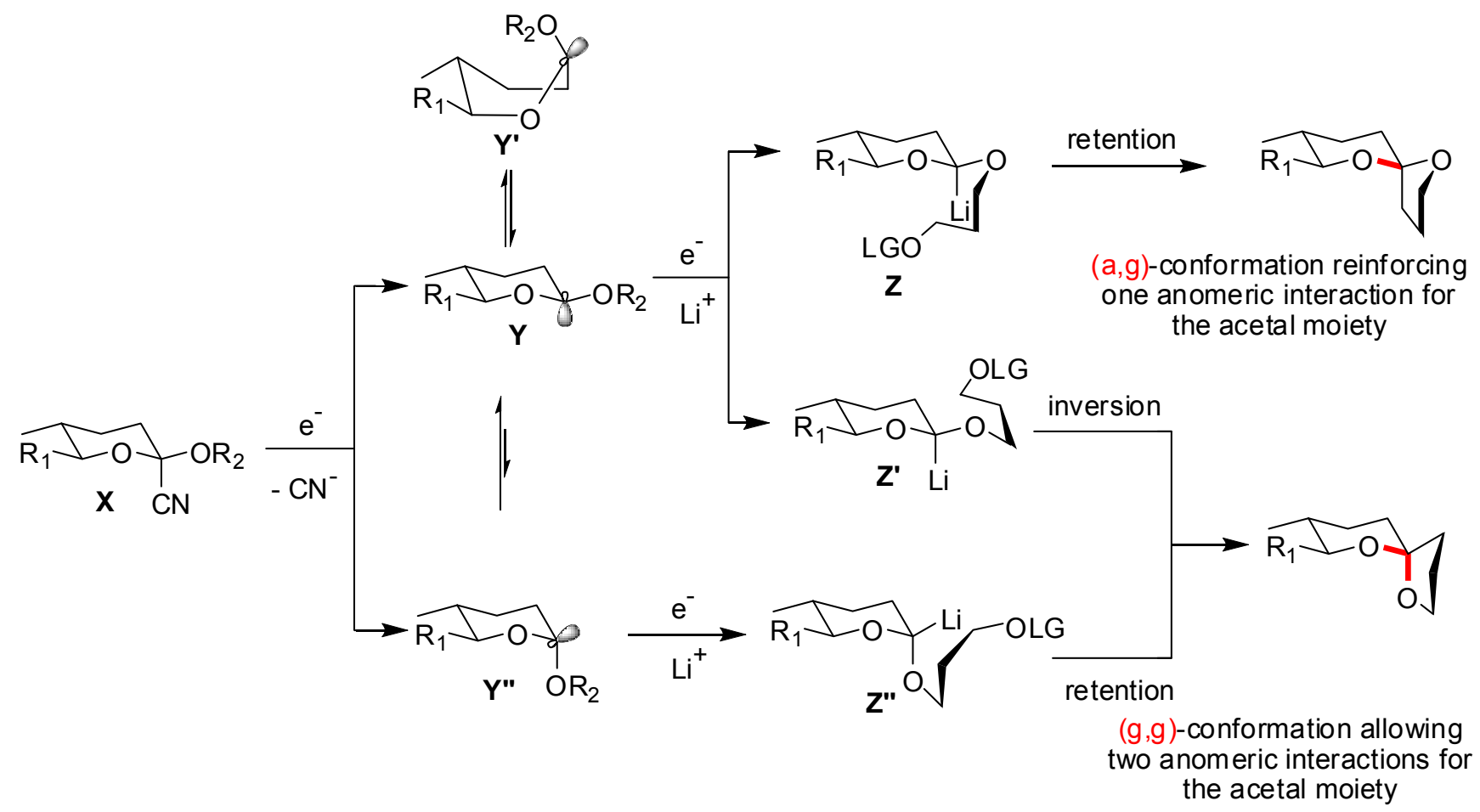

In their non-traditional approach to Attenol A [45] the Rychnovsky group synthesised the nonanomeric epimer of the natural product and then epimerized it to obtain the targeted molecule. This was more efficient than previously developed synthesis and demonstrates the potential of using 
reductive cyclisation reactions to afford non-anomeric spiroketals as well as their thermodynamically stabilized epimers (Scheme 16). After the elaboration of a practical route to spiro-orthoester $\mathbf{8 5}$, treatment with $\mathrm{TMSCN}$ and $\mathrm{BF}_{3} \cdot \mathrm{OEt}_{2}$ furnished the corresponding alcohol, with high regio and chemoselectivity, in $71 \%$ yield. Substitution of the primary alcohol by a phosphonate ester leaving group occurred under mild conditions to afford 86 in $97 \%$ yield. After addition of LiDBB, the reductive cyclization occurred at $-78^{\circ} \mathrm{C}$ to deliver the $(\mathrm{a}, \mathrm{g})$-spiroketal 87 as the major product in a remarkable 94\% yield. The minor products were identified as the (g,g)-epimer and cyanoacetal 89 resulting from the competitive reduction of the phosphate group. GC analysis of the crude mixture established a 78:1 ratio of $(\mathrm{a}, \mathrm{g})$ - to $(\mathrm{g}, \mathrm{g})$-spiroketal underlining the potential of this powerful approach. Equilibration toward the configuration of the natural product occurred in methanol, in the presence of PPTS and provided, after cleavage of protecting groups, the bicyclic derivative 90 together with spiroketal 91. Attempts to suppress this competitive cyclization were unsuccessful and the mixture was used in the next reactions to complete the total synthesis of Attenol A.

Scheme 16. Synthesis of the spiroketal core of Attenol A according to Rychnovsky et al.<smiles>[R]C1CCOC2(CC[C@@H](C)[C@H]([C@H]3COC(C)(C)O3)O2)O1</smiles>

85

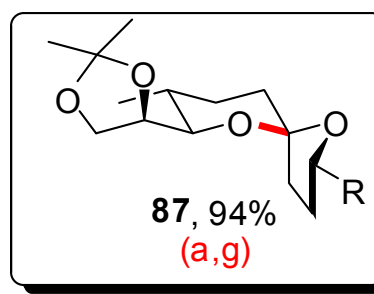

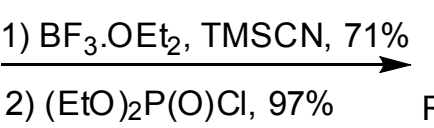

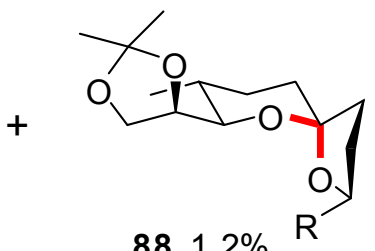

$(g, g)$<smiles>[R]OC(=O)O[C@]1(C)CC[C@@H](C)[C@H]([C@H]2COC(C)(C)O2)O1</smiles>

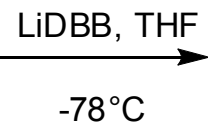

86<smiles>[R]C(CC)OC1(C)CC[C@@H](C)[C@H]([C@H]2COC(C)(C)O2)O1</smiles>

$890.4 \%$

\footnotetext{
PPTS

$\mathrm{MeOH}$

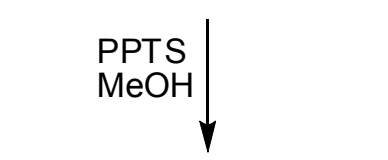

$\mathrm{R}$<smiles>C[C@@H](O)CC[C@@]12CC[C@@H](C)[C@H](O1)[C@H](CO)O2</smiles>

90

$1: 6$ ratio, yield not reported next reactions done on the crude
}

In 2007, the $(\mathrm{a}, \mathrm{g})-[5,6]$-spiroketal core of pectenotoxins PTX1-3 and PTX6 was obtained by Rychnovsky and co-workers using the same methodology [46]. In this case, displacement of spiroorthoesther 92 by TMSCN afforded two regioisomers 93 and 94 in 50\% and 28\% yield, respectively (Scheme 17). This lack of selectivity was attributed to the fact that 92 was less hindered than the previously studied intermediates. Treatment of the major cyanoacetal with LiDBB at low temperature furnished the $(\mathrm{a}, \mathrm{g})$-spiroketal as a single isomer, in $76 \%$ yield. 
Epimerization of 95 under acidic conditions was also possible in this case and delivered the energetically favoured (g,g)-spiroketal 97 in 83\% yield, corresponding to spiroketal core of other members of the pectenotoxins family (PTX4 and PTX7). Valuation of the minor cyanoacetal 94 was realised by its conversion into the (a,a)-[6,6]-spiroketal 96 (two C-O bonds of the spiroketal unit occupying equatorial positions) in a modest but non-optimized $36 \%$ yield, thus extending the scope of this methodology.

Scheme 17. Synthesis of the spiroketal core of pectenotoxins according to Rychnovsky et al.

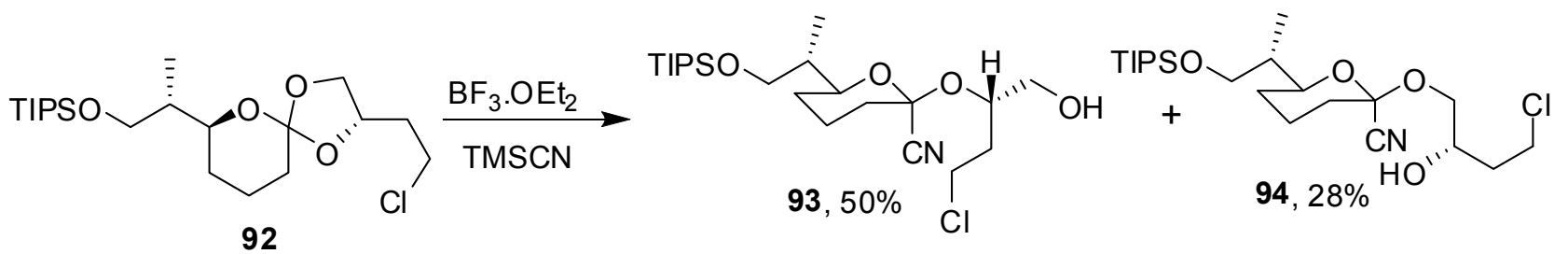

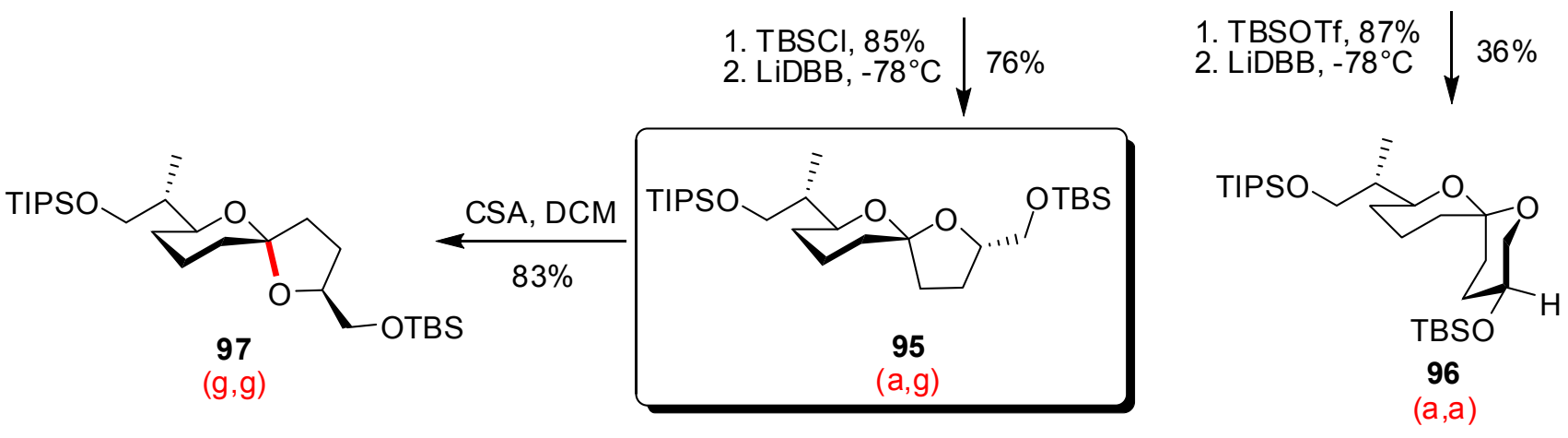

Following their synthesis of the nonanomeric (a,g)-spiroketal core of the pectenotoxins [47] the group of Pihko further explored the preparation of nonanomeric [6,5]-spiroketals through kinetic control in acid catalyzed spirocyclization reactions [48]. Treatment of mixed ketal-alcohols under acid catalysis led to the formation of the nonanomeric spiroketals if the acid was carefully tuned and in aqueous THF medium (Scheme 18).

In particular, treatment of a mixture of methyl ketals $98 \mathrm{a}$ and $98 \mathrm{~b}$, in the presence of trichloroacetic acid, led the nonanomeric (a,g)-spiroketal 101 as the major isomer if the reaction was carried out in aqueous THF. Non aqueous conditions predominantly led to the formation of the anomeric isomers 99 and 100. In the presence of acetonitrile, the nonanomeric spiroketal 101 could also be obtained in good yield by decreasing the temperature to $0^{\circ} \mathrm{C}$. The above conditions have also been successfully applied to the allyl-substituted precursor 102 to deliver the spiroketals 103 and 104 in 35 and 46\% yield, respectively. 
Scheme 18. Synthesis of nonanomeric [5,6]-spiroketals according to Pihko et al.

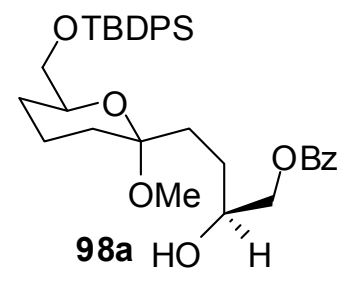

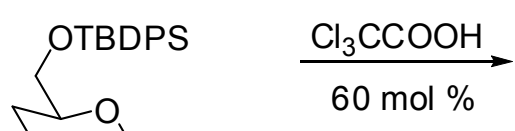

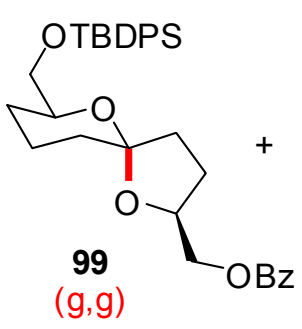

THF / $\mathrm{H}_{2} \mathrm{O}(4: 1)$

98b HO "H

$\mathrm{dr}=2.5: 1$

$\mathrm{MeCN} / \mathrm{H}_{2} \mathrm{O}(4: 1), 0^{\circ} \mathrm{C}$

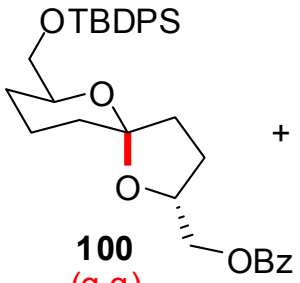

$(g, g)$

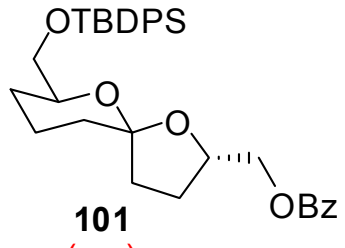

$(\mathrm{a}, \mathrm{g})$

$99: 100: 101=23 \%: 23 \%: 49 \%$

$99: 100: 101=29 \%: 26 \%: 43 \%$
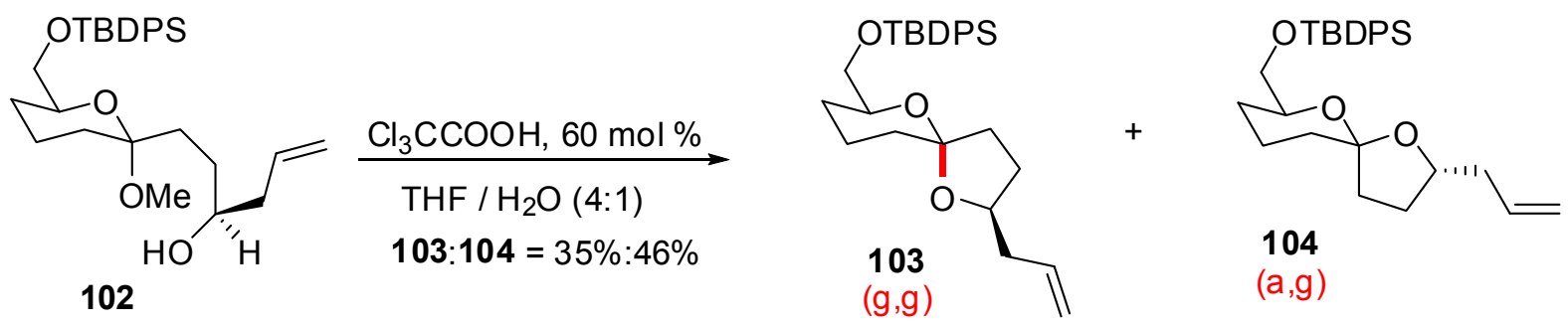

Another strategy was developed by the group of Mootoo [49] to produce spiroketals of various sizes and configurations through a iodoetherification/dehydroiodination sequence (Scheme 19).

Scheme 19. Synthesis of spiroketals according to Mootoo et al.<smiles>[R]OCC/C=C/C/C=C/[C@H](O)CO[R6]#N</smiles><smiles>[R]OCCC(I)[C@H]1CC=C[C@@H](CO[Na])O1</smiles>
106, $\mathrm{R}=\mathrm{PMB}) \mathrm{DDQ}$ 107, $\mathrm{R}=\mathrm{H} \quad 68 \%, 2$ steps<smiles>CC(C)OC[C@H]1C=CCC2(CCCO2)O1</smiles>

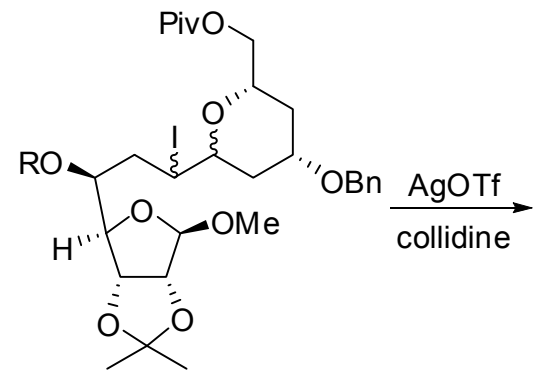

110, $\mathrm{R}=\mathrm{Ac}) \mathrm{K}_{2} \mathrm{CO}_{2}, \mathrm{MeOH}$

111, $\mathrm{R}=\mathrm{H}$ 60\%, 2 steps

$\mathrm{BnO}$

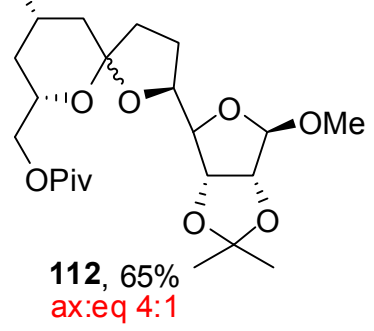


Scheme 19. Cont.

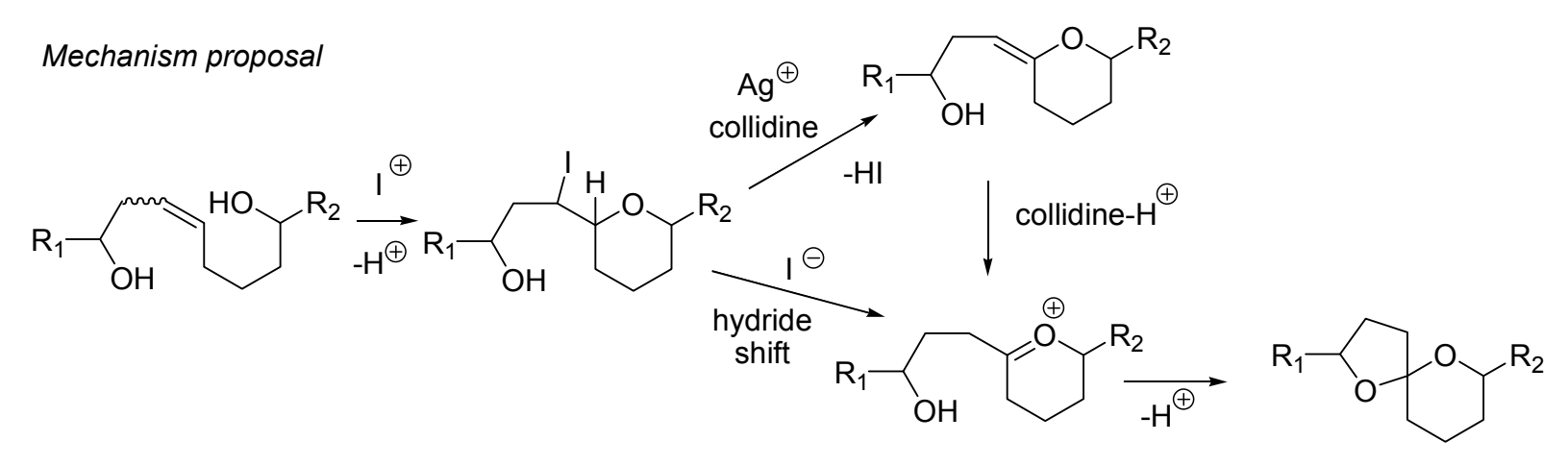

The starting hydroxyalkenes, obtained through cross-metathesis, were treated with iodonium dicollidine perchlorate (IDCP) to provide mixtures of diastereoisomeric iodinated intermediates 106 and 110. The NMR data did not allow for distinction between the possible regioisomers but their structures were tentatively assigned to the 5-exo-trig cyclized products based on previous investigations [50]. Exposure of these iodo-alkenes to silver triflate in the presence of collidine led to the formation of [5,6]-spiroketals in moderate to good yields, with various ratios of $(\mathrm{a}, \mathrm{g})$ - and $(\mathrm{g}, \mathrm{g})$ stereoisomers. The authors observed that the stereoselectivity of the spiroketalisation was not affected by the stereochemistry of the iodinated precursor which is consistent with an oxycarbenium ion mediated mechanism. They proposed two pathways that could lead to this intermediate: i) either protonation of an initially formed exocyclic enol ether (resulting from $\beta$-elimination of HI) or ii) via $\mathrm{Ag}^{+}$assisted iodide $\mathrm{S}_{\mathrm{N}} 1$ departure with simultaneous hydride shift from the iodo ether intermediate.

Scheme 20. Synthesis of the LM spiroketal of ciguatoxin CTX3C according to Domon et al.

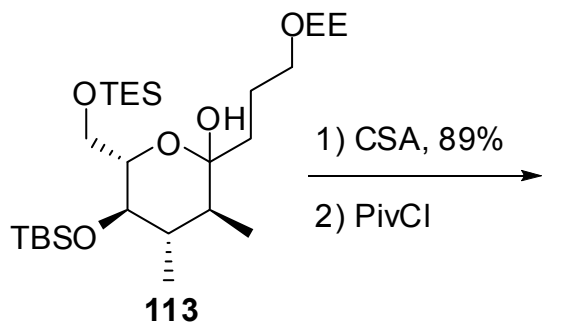
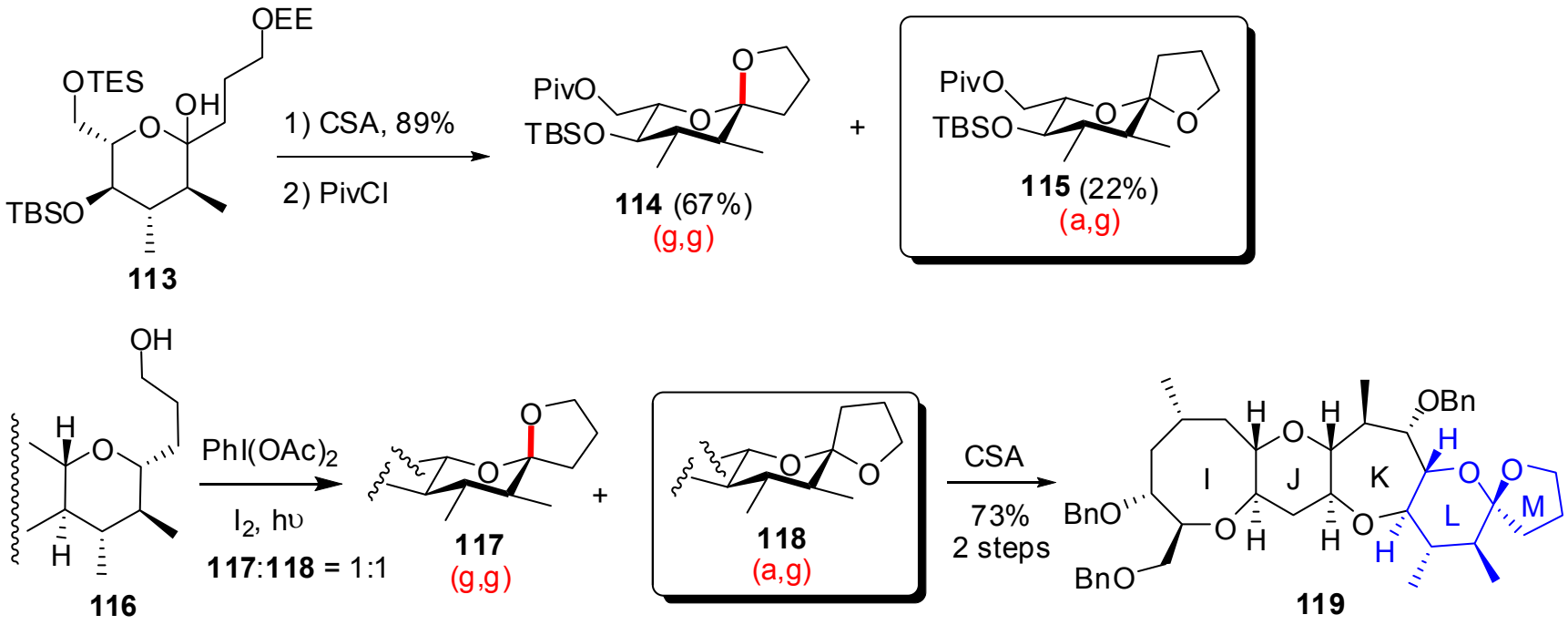

In their studies toward the synthesis of the IJLM-rings portion of the polycyclic ether ciguatoxin CTX3C [51], Domon and co-workers addressed the preparation of the terminal anomeric LM spiroketal (Scheme 20) [52]. Acidic treatment of hemiketal 113 led to a mixture of spiroketals with a 3:1 ratio in favour of the $(\mathrm{g}, \mathrm{g})$-isomer 114. Working on a more advanced intermediate 116, 
spirocyclization was achieved through an oxidative radical pathway to provide a 1:1 mixture of both epimeric spiroketals 117 and 118. Kinetic control conditions could be assumed for the formation of the $(\mathrm{a}, \mathrm{g})$-spiroketal as conversion to the more stable $(\mathrm{g}, \mathrm{g})$-epimer was obtained after subjection to CSA.

Okaspirodiol (120) was isolated by the group of Beder from Streptomyces sp. strain Gö TS 19 as a secondary metabolite and its structure was assigned on the basis of NMR, mass spectroscopy and Xray analyses, after derivatization (Scheme 21) [53]. The (g,g)-spiroketal 120 was readily isomerized under mild acidic conditions to furnish a set of new structures. After $48 \mathrm{~h}$ in deuterated chloroform, 3 new isomers were formed and separated by column chromatography to yield a 29:47:5:19 ratio of 120:122:121:123. Interestingly, okaspirodiol was not isolated as its thermodynamically favored trans (C3, C4) configuration but this structure was the major isomer under acidic conditions. The epimerization at $\mathrm{C}(3)$ position was completely prevented after per-benzylation and the equatorial spiroketal was obtained with up to $40 \%$ yield, after treatment with methanolic $\mathrm{HCl}$. This increase in the proportion of the non-anomeric $(\mathrm{a}, \mathrm{g})$-spiroketal results from the suppression of hydrogen bonding stabilization between the hydroxymethyl group at $\mathrm{C}(4)$ and the $\mathrm{O}(6)$ atom. This result underlines the importance of the intramolecular hydrogen bonds in the structural outcome of spiroketal structures and of possible gauche effect between vicinal dioxy substituents, not to mention differential solvent effects.

Scheme 21. Isolation and epimerization of okaspirodiol according to Beder et al.
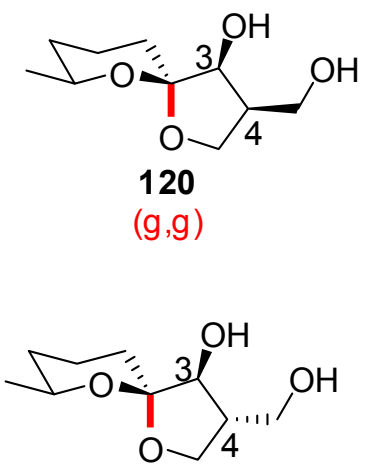

122

$(9, g)$
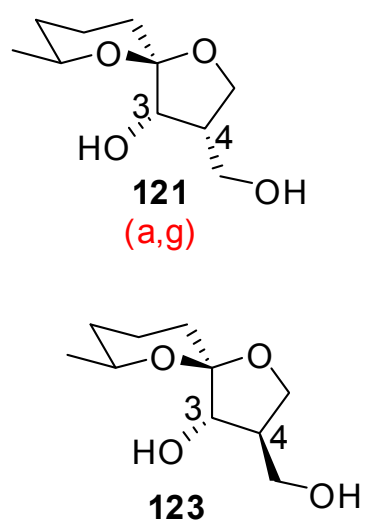

$(\mathrm{a}, \mathrm{g})$

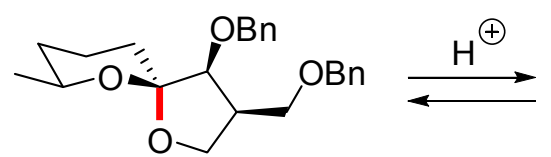

124

$(g, g)$

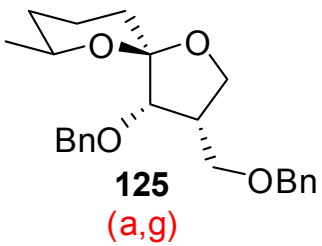

$\mathrm{HCl}, \mathrm{CD}_{3} \mathrm{OD}, 124: 125=60: 40$

$\mathrm{CSA}, \mathrm{CD}_{2} \mathrm{Cl}_{2}, 124: 125=71: 29$

Aculeatins A and B are two epimeric functionalized spiroketals isolated from Amomum aculeatum Roxb. [54], together with Aculeatin C [55] and later Aculeatin D [56]. More recently similar structures, the Aculeatols A-D, have been isolated from the same source. These compounds displayed antiprotozoal activity against Plasmodium and Trypanosoma species as well as antibacterial activity against KB cell lines (Scheme 22) [57]. 
Scheme 22. Diverse members of the aculeatins family.

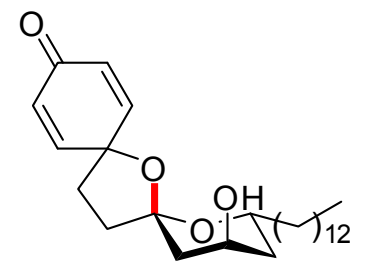

(-)-Aculeatin A (126) $(g, g)$

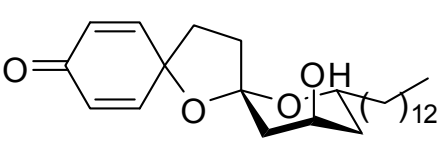

(+)-Aculeatin B (127) $(\mathrm{a}, \mathrm{g})$

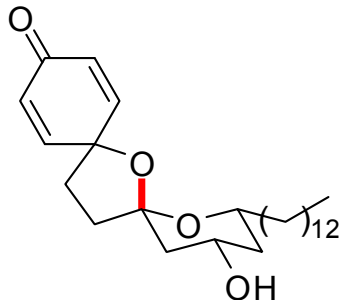

(+)-6-epi-Aculeatin D (128)

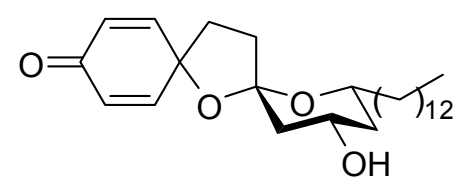

(+)-Aculeatin D (129)

$(a, g)$

$(g, g)$

Many synthetic efforts have been devoted to the construction of their unusual structure, involving a final key oxidative spirocyclisation of phenolic precursors. In the approach developed by Wong et al. [58], rapid treatment of thioacetal 130 with phenyliodine bis(trifluoroacetate) (PIFA) led to a 3.2:1 ratio of epimeric aculeatins $\mathrm{A}$ and $\mathrm{B}$, in favor of the $(\mathrm{g}, \mathrm{g})$-spiroketal structure (Scheme 23). Longer reaction times increased the proportion of the $(\mathrm{g}, \mathrm{g})$-spiroketal such as illustrated by the reaction developed by Marco et al. [59] on the protected diol 132 wich afforded a 5.5:1 ratio of $\mathbf{1 2 6}$ and $\mathbf{1 2 7}$. Analogues of $\mathbf{1 1 7}$ were used as starting materials for the preparation of aculeatin D and 6-epi-acuelatin $\mathrm{D}$ [60]. Starting from enone 131, hydrogenation followed by treatment with PIFA led to a 2.5:1 ratio of $(\mathrm{g}, \mathrm{g})-v s(\mathrm{a}, \mathrm{g})-[6,5]$-spiroketals [61].

Scheme 23. Synthetic approaches to Aculeatins A and B.

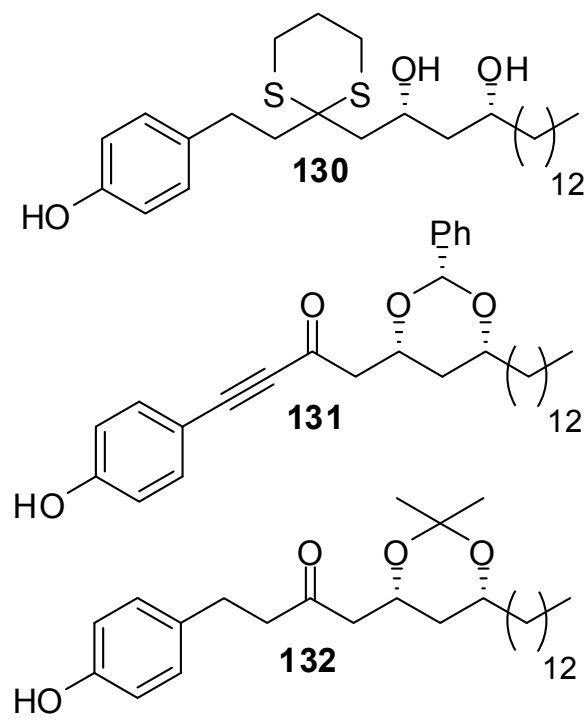

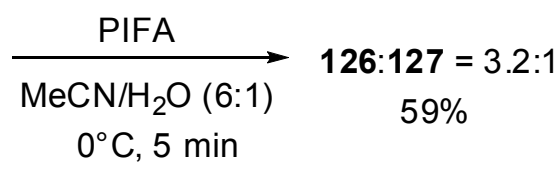

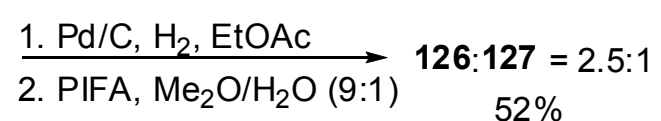

$\mathrm{rt}, 10 \mathrm{~min}$

$52 \%$

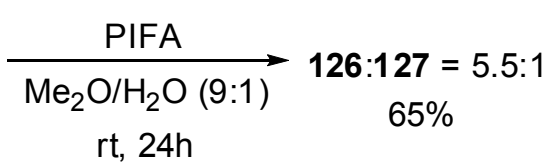

In 2007, Wong et al. [62] proposed a rationalization for the stereochemical outcome of the oxidative spirocyclization to aculeatins (Scheme 24). 
Scheme 24. Mechanism of oxidative spirocyclization according to Wong et al.
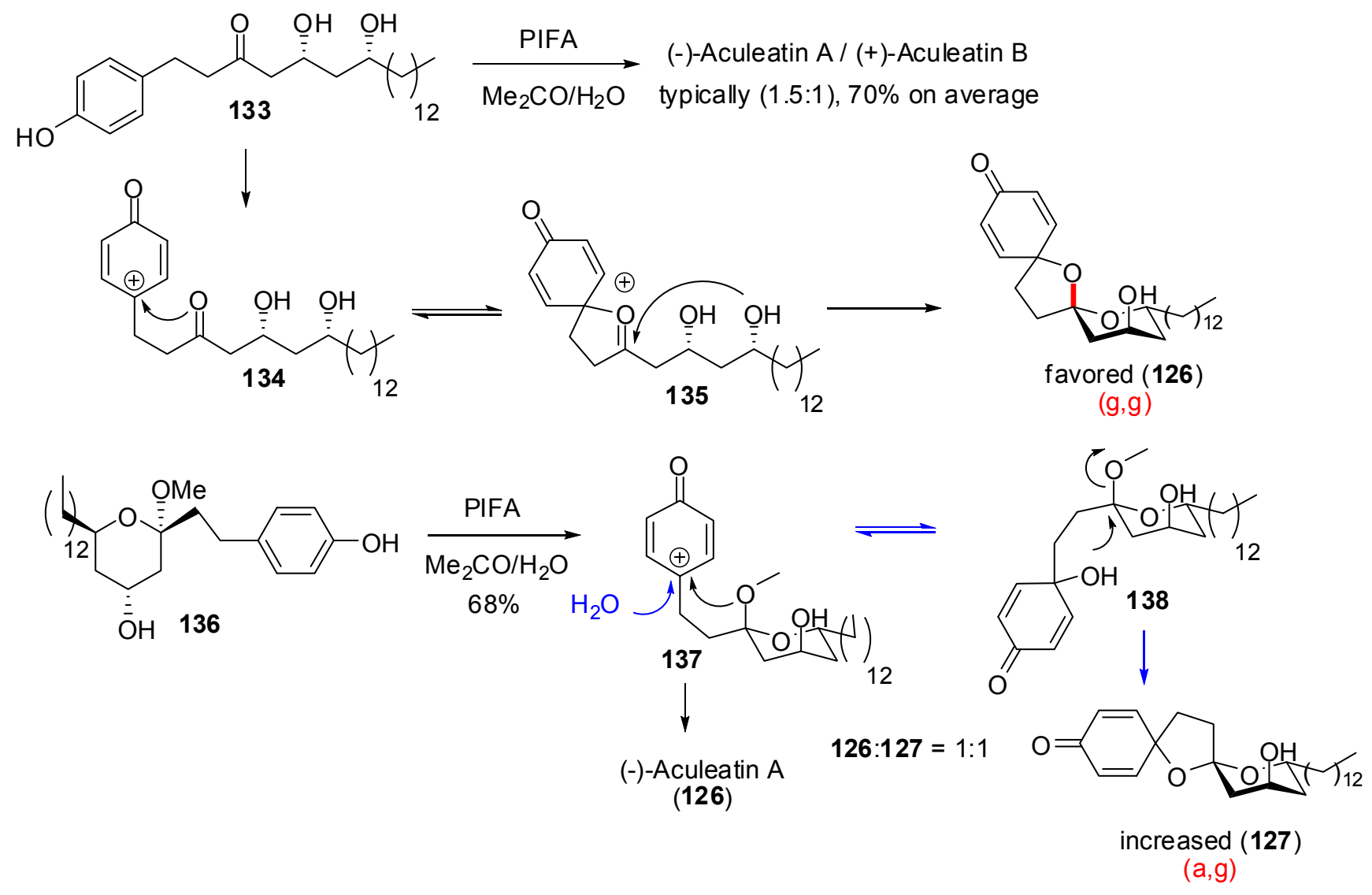

The linear precursor $\mathbf{1 3 3}$ led to a mixture of epimers in favor of the anomeric spiroketal $\mathbf{1 2 6}$ through a pathway involving the bicyclic oxycarbenium cation intermediate 135. Starting from methyl acetal 136, the authors assumed that the methyl ether was less prone to direct attack on the cation intermediate 137, thus favoring water addition to produce the tertiary alcohol 138. Nucleophilic displacement of the methoxy group then led to the (a,g)-spiroketal 127. The authors developed similar route toward aculeatin D and 6-epi-acuelatin D.

The group of Baldwin [63] explored the synthesis of aculeatin D from dihydroxy ketone 139 (Scheme 25). Acid mediated removal of the acetonide delivered hemiketal 141 which stands in equilibrium, in solution, with the linear ketone 140. Further oxidative spirocylization afforded a mixture of $(\mathrm{g}, \mathrm{g})$-spiroketal 128, $(\mathrm{a}, \mathrm{g})$-spiroketal 129 and open chain derivative 142, the ratio depending on the solvent. In acetonitrile, only (g,g)-6-epi-acuelatin D was formed in 33\% yield. In acetone and wet acetone $(\mathrm{a}, \mathrm{g})$ - aculeatin $\mathrm{D}$ was formed and was isolated in up to $19 \%$ yield. 
Scheme 23. Synthesis of aculeatin D and 6-epi-aculeatin D according to Baldwin et al.

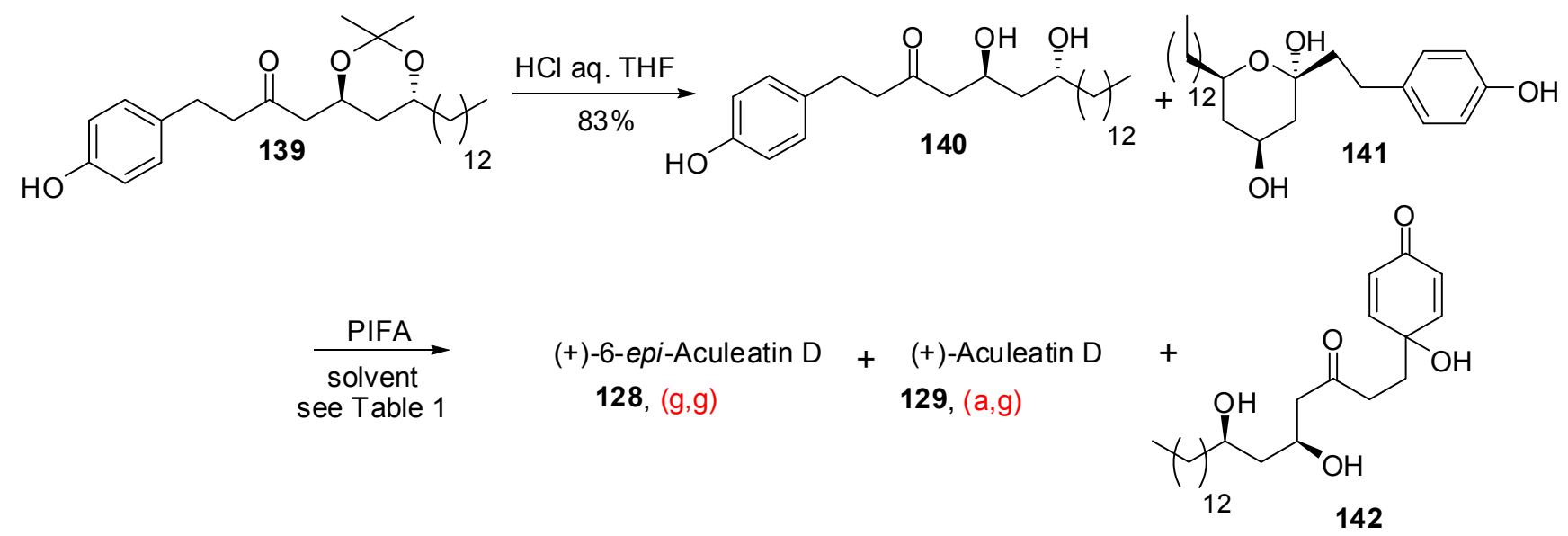

Table 1. Stereochemical dependence on reaction conditions.

\begin{tabular}{lccc}
\hline \multicolumn{1}{c}{ Conditions } & $\mathbf{1 1 4}(\%)$ & $\mathbf{1 1 3}(\%)$ & $\mathbf{1 2 7}(\%)$ \\
\hline $\mathrm{MeCN}, 0^{\circ} \mathrm{C}, 1 \mathrm{~h}$ & 0 & 33 & 15 \\
$\mathrm{MeCN} / \mathrm{H}_{2} \mathrm{O}(6: 1), 0^{\circ} \mathrm{C}, 1 \mathrm{~h}$ & 0 & 29 & 44 \\
Acetone, rt, 20 min & 11 & 40 & 20 \\
Acetone $/ \mathrm{H}_{2} \mathrm{O}(9: 1), \mathrm{rt}, 20 \mathrm{~min}$ & 19 & 43 & 27 \\
\hline
\end{tabular}

Scheme 26. Mechanistic proposal for the oxidative spirocyclization according to Baldwin et al.

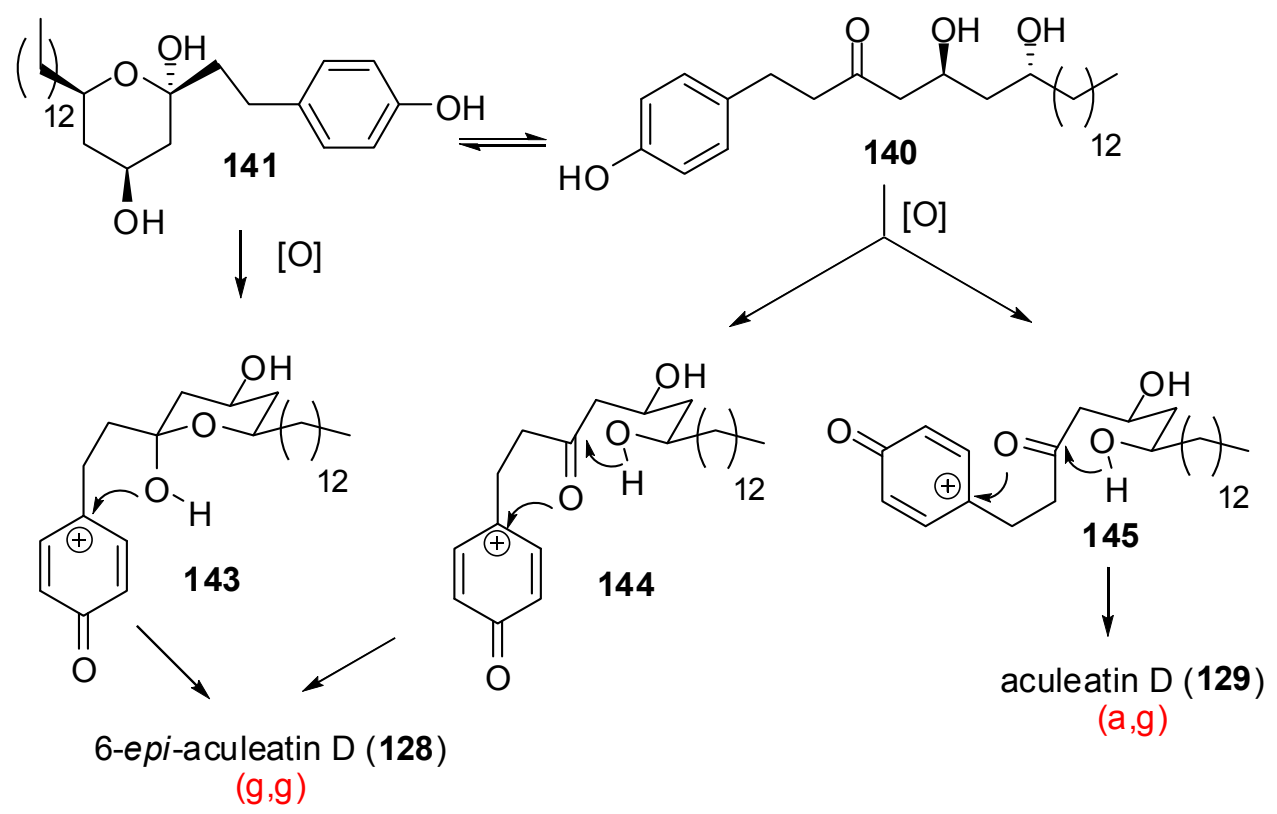

In acetonitrile, hemiketal intermediate $\mathbf{1 4 1}$ is observed whereas in acetone, a mixture of hemiketal 141 and open chain derivative 140 is observed (Scheme 26). After oxidation, the hemiketal can directly react with the phenoxycarbenium cation 143 to deliver the (g,g)-6-epi-aculeatin $\mathrm{D}$, whereas 
two pathways are possible for the open chain carbocation intermediate giving also access to the expected less stable $(\mathrm{a}, \mathrm{g})$-spiroketal.

\section{Conclusions}

Nature is an infinite reservoir of fascinating compounds of biological interest. A large variety of natural products contain $[6,6]$-and [6,5]-spiroketals with various configurations that enjoy or not from conformational anomeric stabilization effects for their acetal moiety. Steric factors and gauche effects also contribute to the relative stability of polysubstituted spiroketals. These fragments are very important for the biological activity of compounds that contain them. Many synthetic efforts have thus been devoted to their stereoselective preparation. Whereas the access to the most stable stereoisomers is generally warranted by the use of acidic conditions that permit equilibration of all stereoisomers into the most stable one (ones), the synthesis of less stable stereoisomers is more challenging. It requires stereoselective acetal forming reactions under media that do not allow for acetal heterolysis, or concomitant reactions giving derivatives that can be obtained only from the less stable acetal stereoisomers. This can be realized with adequately substituted systems that can generate tricyclic structures in irreversible reactions.

\section{References and Notes}

1. For reviews, see e.g.: a) Boivin, T.L.B. Synthetic routes to tetrahydrofuran, tetrahydropyran, and spiroketal units of polyether antibiotics and a survey of spiroketals of other natural products. Tetrahedron 1987, 43, 3309-3362; b) Perron, F.; Albizati, K.F. Chemistry of spiroketals. Chem. Rev. 1989, 89, 1617-1661; c) Vaillancourt, V.; Pratt, N.E.; Perron, F; Albizati, K.F. The total synthesis of spiroketal-containing natural products. Total Synth. Nat. Prod. 1992, 533-691; d) N. Haddad, N.; Abramovich, Z.; Ruhman, I. Novel stereoselective synthesis of spiroethers and spiroketals. Recent Res. Dev. Org. Chem. 1997, 1, 35-42.

2. a) Pettit, G. R.; Cichacz, Z. A.; Gao, F.; Herald, C. L.; Boyd, M. R.; Schmidt, J. M.; Hooper, J. N. A. Isolation and structure of spongistatin 1. J. Org. Chem. 1993, 58, 1302-1304; b) Pettit, G. R.; Cichacz, Z. A.; Gao, F.; Herald, C. L.; Boyd, M. R. Isolation and structure of the remarkable human cancer cell growth inhibitors spongistatins 2 and 3 from and eastern Indian ocean Spongia sp. J. Chem. Soc. Chem. Commun. 1993, 1166-1168; c) Kobayashi, M.; Aoki, S.; Sakai, H.; Kawazoe, K.; Kihara, N.; Sasaki, T.; Kitagawa, I. Altohyrtin A, a potent anti-tumor macrolide from the okinawan marine sponge Hyrtios altum. Tetrahedron Lett. 1993, 34, 2795 2798; d) Kobayashi, M.; Aoki, S.; Sakai, H.; Kihara, N.; Sasaki, T.; Kitagawa, I. Altohyrtins B and $\mathrm{C}$ and 5-desacetylaltohyrtin $\mathrm{A}$, potent cytotoxic macrolide congeners of altohyrtin A, from the Okinawan marine sponge Hyrtios altum. Chem. Pharm. Bull. 1993, 41, 989-991; e) Kobayashi, M.; Aoki, S.; Kitagawa, I. Absolute stereostructures of altohyrtin A and its congeners, potent cytotoxic macrolides from the Okinawan marine sponge Hyrtios altum. Tetrahedron Lett. 1994, 35, 1243-1246; f) Kobayashi, M.; Aoki, S.; Gato, K.; Kitagawa, I. Marine natural products. XXXVIII. Absolute stereostructures of altohyrtins A, B, and C and 5desacetylaltohyrtin A, potent cytotoxic macrolides, from the Okinawan marine sponge Hyrtios 
altum. Chem. Pharm. Bull. 1996, 44, 2142-2149; g) Fusetani, N.; Shinoda, K.; Matsunaga, S. Bioactive marine metabolites. 48. Cinachyrolide A: a potent cytotoxic macrolide possessing two spiro ketals from marine sponge Cinachyra sp. J. Am. Chem. Soc. 1993, 115, 3977-3981.

3. For a review of methodologies developed up to 2004, see: Aho, J.E.; Pihko, P.M.; Rissa, T.K. Nonanomeric spiroketals in natural products: structures, sources, and synthetic strategies. Chem. Rev. 2005, 105, 4406-4440.

4. a) Schleyer, P.V.R.; Jemmis, J.E.; Spitznagel, G.W. Do anomeric effects involving the secondrow substituents, chlorine, mercapto, and phosphino exist? Stabilization energies and structural preferences. J. Am. Chem. Soc. 1985, 107, 6393-6394; b) Apeloig, Y.; Schleyer, P.V.R.; Pople, J.A. Molecular orbital theory of the electronic structure of molecules. 35. $\beta$-Substituent effects on the stabilities of ethyl and vinyl cations. Comparison with isoelectronic methyl boranes. The relative importance of hyperconjugative and inductive effects. J. Am. Chem. Soc. 1977, 99, 59015909; c) Beckhaus, H.-D.; Dogan, B.; Verevkin, S.; Hädrich, J.; Rückardt, C. Dependence of anomeric stabilization on structure in acetals. Angew. Chem. Int. Ed. Engl. 1990, 29, 320-321; d) Hati, S.; Datta, D. Anomeric effect and hardness. J. Org. Chem. 1992, 57, 6056-6057; e) http://webbook.nist.gov.

5. Jungius, C. L. Rearrangement between some isomers glucosederivatives and the muta-rotation of the kinds of sugar [machine translation]. Z. Phys. Chem. 1905, 52, 97-108.

6. Edward, J. T. Stability of glycosides to acid hydrolysis Chem. Ind. (London) 1955, 1102-1104.

7. a) Lemieux, R.U.; Chü, N.J. Abstr. Papers Am. Chem. Soc. Meeting 1958, 31N; b) Lemieux, R.U. Effects of unshared pairs of electrons and their salvation on conformational equilibria. Pure Appl. Chem. 1971, 25, 527-548; c) Jeffrey, G.A.; Pople, J.A.; Radom, L. Application of ab initio molecular orbital theory to the anomeric effect. Comparison of theoretical predictions and experimental data on conformations and bond lengths in some pyranoses and methyl pyranosides. Carbohydr. Res. 1972, 25, 117-131.

8. a) Wolfe, S., Whangbo, M.-H.; Mitchell, D.J. Molecular orbitals from group orbitals. Part VII. On the magnitudes and origins of the "anomeric effects", "reverse anomeric effects", and C-X and $\mathrm{C}-\mathrm{Y}$ bond lengths in $\mathrm{X}-\mathrm{CH}_{2}-\mathrm{YH}$. Carbohydr. Res. 1979, 69, 1-26; b) Fuchs, B.; Elleincweig, A. Structure and conformation of heterocycles. Generalized anomeric effects in 1,4-dioxanes bearing polar substituents. Nouv. J. Chim. 1979, 3, 145-147.

9. a) Dewar, M.J.S. Chemical implication of $\sigma$ conjugation. J. Am. Chem. Soc. 1984, 106, 669-682;

b) Cramer, C.J. Hyperconjugation as it affects conformational analysis. THEOCHEM 1996, 370, 135-146.

10. Salzner, U.; Schleyer, P.V.R. Generalized anomeric effects and hyperconjugation in $\mathrm{CH}_{2}(\mathrm{OH})_{2}$, $\mathrm{CH}_{2}(\mathrm{SH})_{2}, \mathrm{CH}_{2}(\mathrm{SeH})_{2}$ and $\mathrm{CH}_{2}(\mathrm{TeH})_{2}$. J. Am. Chem. Soc. 1993, 115, 10231-10236.

11. Deslongchamps, P.; Rowan, D.D.; Pothier, N.; Sauve, T.; Saunders, J.K. 1,7-dioxaspiro[5.5] undecanes. An excellent system for the study of stereoelectronic effects (anomeric and exoanomeric effects) in acetals. Can. J. Chem. 1981, 59, 1105-1121.

12. a) Dubois, J.E.; Cossé-Barbi, A.; Watson, D.G. When local crowding reinforces an anomeric effect. Tetrahedron Lett. 1989, 30, 167-170; b) Salzner, U., Schleyer, P.V.R. Ab initio examination of anomeric effects in tetrahydropyrans, 1,3-dioxanes and glucose. J. Org. Chem. 1994, 59, 2138-2155. 
13. a) Bailey, W.F.; Eliel, E.L. Conformational analysis. XXIX. 2-Substituted and 2,2-disubstituted 1,3-dioxanes. Generalized and reverse anomeric effects. J. Am. Chem. Soc. 1974, 96, 1798-1806; b) Praly, J.P.; Lemieux, R.U. Influence of solvent on the magnitude of the anomeric effect. Can. J. Chem. 1987, 65, 213-223; c) Wiberg, K.B.; Marquez, M. The energy components of the anomeric effect for 2-methoxytetrahydropyran. An experimental comparison of the gas phase and solutions. J. Am. Chem. Soc. 1994, 116, 2197-2198; d) Molteni, C.; Parrinello, M. Glucose in aqueous solution by first principles molecular dynamics. J. Am. Chem. Soc. 1998, 120, 21682171; e) Woodcock, H.L.; Moran, D.; Pastor, R.W.; Mackerell, A.D. Jr.; Brooks, B.R. Ab initio modeling of glycosyl torsions and anomeric effects in a model carbohydrate: 2-ethoxy tetrahydropyran. Biophys. J. 2007, 93, 1-10.

14. Booth, H.; Khedhair, K.A. Endo-anomeric and exo-anomeric effects in 2-substituted tetrahydropyrans. J. Chem. Soc., Chem. Comm. 1985, 467-468.

15. Tvaroska, I.; Carver, J.P. The anomeric and exo-anomeric effects of the hydroxyl group and the stereochemistry of the hemiacetal linkage. Carbohydr. Res. 1998, 309, 1-9.

16. a) Benedict, W.S.; Gailar, N.; Plyer, E.K. Rotation-vibration spectra of deuteriated water vapour. J. Chem. Phys. 1956, 24, 1139-1165; b) Clough, S.A.; Beers, Y.; Klein, G.P.; Rothman, L.S. Dipole moment of water from Stark measurements of water, monodeuterated water and deuterated water. J. Chem. Phys. 1973, 59, 2254-2259; c) Bicerano, J.; Marynick, D.S.; Lipscomb, W.N. Basis set and electron correlation effects on the total electron density in water, hydrogen sulphide and borane. J. Am. Chem. Soc. 1978, 100, 732-739; d) Wiberg, K.B.; Rablen, P.R. Comparison of atomic charges derived via different procedures. J. Comput. Chem. 1993, 14, 1504-1518; e) Martin, F., Zipse, H. Charge distribution in the water molecule - a comparison of methods. J. Comput. Chem. 2004, 26, 97-105.

17. a) Bock, H., Mollère, P., Becker, G.; Fritz, G. Photoelectron spectra and molecular properties. XX. Dimethyl ether, methoxysilane, and disiloxane. J. Organomet. Chem. 1973, 61, 113-125; b) Tsuboyama, A.; Takeshita, K.; Konada, S.; Kimura, M. Ab initio gradient calculation of the molecular structures of dimethyl ether and dimethyl sulphide. Bull. Chem. Soc. Jpn. 1984, 57, 3589-3590; c) Clark, S.A.C.; Bawagan, A.O.; Brian, C.E. The valence orbital momentum distribution binding enegy spectra of dimethyl ether by electron momentum spectroscopy: an investigation of the methyl inductive effect. Chem. Physics 1989, 137, 407-426; d) Tsuzuki, S.; Uchimaru, T.; Tanabe, K., Yliniemela, A. Comparison of atomic charge distributions obtained from different procedures: basis set and electron correlation effects. THEOCHEM 1996, 365, 8188.

18. a) Vila, A.; Mosquera, R.A. Atoms in molecules interpretation of the anomeric effect in the O-CO unit. J. Comput. Chem. 2007, 28, 1516-1530; b) Trapp, M.L.; Watts, J.K.; Weinberg, N.; Pinto, B.M. Component analysis of the X-C-Y anomeric effect ( $\mathrm{X}=\mathrm{O}, \mathrm{S} ; \mathrm{Y}=\mathrm{F}, \mathrm{OMe}, \mathrm{NHMe})$ by DFT molecular orbital calculations and natural bond orbital analysis. Can. J. Chem. 2006, 84, 692-701.

19. a) Zefirov, N.S.; Samoshin, V.V.; Subbotin, O.A.; Baranenkov, V.I.; Wolfe, S. The gauche effect on the nature of the interactions between electronegative substituents in trans-1,2-disubstituted cyclohexanes. Tetrahedron 1978, 34, 2953-2959; b) Juaristi, E. The attractive and repulsive gauche effect. J. Chem. Educ. 1979, 56, 438-441; c) Wiberg, K.B.; Murcko, M.A.; Laidig, K.E.; 
MacDougall, P.J. Origin of the gauche effect in substituted ethanes and ethenes. J. Phys. Chem. 1990, 94, 6956-6959; d) Juaristi, E.; Antunez, S. Conformational analysis of 5-substituted 1,3dioxanes. 6. Study of the attractive gauche effect in O-C-C-O. Tetrahedron 1992, 48, 5941-5950; e) Svenson, S.; Schaefer, A.; Iuhrhop, J.H. Conformational effects of 1,3-syn-diaxial repulsion and 1,2-gauche attraction between hydroxyl groups in nanomolecular $N$-octyl-D-hexonamide solutions. A 13-C and 1-H NMR spectroscopy study. J. Chem. Soc., Perkin Trans. 2 1994, 10231028; f) Gil, F.P.S.C.; Da Costa, A.M.A.; Teixeira-Dias, J.J.C. Conformational analysis of $\mathrm{C}_{\mathrm{m}} \mathrm{H}_{2 \mathrm{~m}}-\mathrm{OCH}_{2} \mathrm{CH}_{2} \mathrm{OH}(\mathrm{m}=1-4)$ : the role of the $\mathrm{CH}$... O intermolecular interactions. J. Phys. Chem. 1995, 99, 8066-8070; g) Sasanuma, Y.; Sugita, K. The attractive gauche effect in ethylene oxides. Polym. J. (Toxyo, Japan) 2006, 38, 983-988.

20. a) Cramer, C.J.; Truhlar, D.G.; French, A.D. Exo-anomeric effects on energies and geometries of different conformations of glucose and related systems in the gas phase and aqueous solution. Carbohydr. Res. 1997, 298, 1-14. b) Plavec, J.; Thibaudeau, C.; Chattopadhyaya, J. How do the energetics of the stereoelectronic gauche and anomeric effects modulate the conformation of nucleosides and nucleotides? Pure Appl. Chem. 1996, 68, 2137-2144.

21. a) Sellers, H.; Saebø, S.; Pulay, P. The ring puckering potential of oxetane: local correlation results. Chem. Phys. Lett. 1986, 132, 29-31; b) Sellers, H.; Almlöf, J.; Saebø, S.; Pulay, P. Ring puckering potential of oxetane: TZ + nP/MP4 (SDQ) results. J. Phys. Chem. 1987, 91, 42164218; c) Mastryukov, V.S.; Boggs, J.E. Structure and conformation of some saturated four membered rings, $\mathrm{CH}_{2} \mathrm{CH}_{2} \mathrm{CH}_{2} \mathrm{X}$, THEOCHEM 1995, 338, 235-248.

22. a) Engerholm, G.G.; Luntz, A.C.; Gwinn, W.D.; Harris, D.O. Ring puckering in five-membered rings. II. Microwave spectrum, dipole moment and barrier to pseudorotation in tetrahydrofuran. J. Chem. Phys. 1969, 50, 2446-2457; b) Infarnet, Y.; Dunlan, J.C.; Delmau, J.; Huet, J. Conformation of methyltetrahydrofurans. Compt. Red. Acad. Sci. Ser. C 1969, 269, 1415-1418; c) Luger, P.; Buschmann, J. Twist conformation of tetrahydrofuran in the crystal form. Angew. Chem. 1983, 95, 423-424. d) Rayón, V.M.; Sordo, J.A. Pseudorotation motion in tetrahydrofuran: An ab initio study. J. Chem. Phys. 2005, 122, 204303-1-8.

23. a) Lambert, J.B.; Keske, R.G.; Weary, D.K. Conformational characterization of simple group VI heterocycles. J. Am. Chem. Soc. 1967, 89, 5921-5924; b) Lambert, J.B.; Mixan, C.E.; Johnson, D.H. Conformational analysis of selenanes and telluranes. J. Am. Chem. Soc. 1973, 95, 46344639; c) Freeman, F.; Kasner, M.L.; Hehre, W.J. An ab initio theory and density functional theory (DFT) study of conformers of tetrahydro-2H-pyran. J. Phys. Chem. A 2001, 105, 1012310132; d) Ionescu, A.R.; Bérces, A.; Zgierski, M.Z.; Whitfield, D.M.; Nakada, T. Conformational pathways of saturated six-membered rings. A static and dynamical density functional study. J. Phys. Chem. A 2005, 109, 8096-8105.

24. For reviews, see e.g.: a) Yeung, K.-S.; Paterson, I. Advances in the total synthesis of biologically important marine macrolides. Chem. Rev. 2005, 105, 4237-4313; b) Pietruska, J. Spongistatins, cynachyrolides, or altohyrtins? Marine macrolides in cancer therapy. Angew. Chem. Int. Ed. 1998, 37, 2629-2636; c) Morris, J.C.; Nicholas, G.M.; Phillips, A.J. Marine natural products: synthetic aspects. Nat. Prod. Rep. 2007, 24, 87-108; d) Gerber-Lemaire, S., Vogel, P. Spongistatins : biological activity and synthetic studies. Compt. Rend. Acad. Sci. 2008, in press. 
25. Paterson, I.; Chen, D. Y.-K.; Coster, M. J.; Aceña, J. L.; Bach, J.; Gibson, K. R.; Keown, L. E.; Oballa, R. M.; Trieselmann, T.; Wallace, D. J.; Hodgson, A. P.; Norcross, R. D. Stereocontrolled total synthesis of (+)-altohyrtin A/spongistatin 1. Angew. Chem., Int. Ed. 2001, 40, 4055-4060.

26. a) Paterson, I.; Coster, M.J.; Chen, D.Y.-K.; Oballa, R.M.; Wallace, D.J.; Norcross, R.D. The stereocontrolled total synthesis of altohyrtin A/spongistatin 1: the AB-spiroacetal segment. Org. Biomol. Chem. 2005, 3, 2399-2409; b) Paterson, I.; Coster, M.; Chen, D. Y.-K.; Gibson, K. R.; Wallace, D. The stereocontrolled total synthesis of altohyrtin A/spongistatin 1: the CDspiroacetal segment. Org. Biomol. Chem. 2005, 3, 2410-2419; c) Paterson, I.; Coster, M. J.; Chen, D. Y.-K.; Acena, J. L.; Bach, J.; Keown, L.; Trieselmann, T. The stereocontrolled total synthesis of altohyrtin A/spongistatin 1: the southern hemisphere EF segment. Org. Biomol. Chem. 2005, 3, 2420-2430; d) Paterson, I.; Chen, D. Y.-K.; Coster, M. J.; Acena, J. L.; Bach, J.; Wallace, D. The stereocontrolled total synthesis of altohyrtin A/spongistatin 1: fragment couplings, completion of the synthesis, analogue generation and biological evaluation. Org. Biomol. Chem. 2005, 3, 2431-2440.

27. Ball, M.; Gaunt, M.J.; Hook, D.F.; Jessiman, A.S.; Kawahara, S.; Orsini, P.; Scolaro, A.; Talbot, A.C.; Tanner, H.R.; Yamanoi, S.; Ley, S.V. Total synthesis of spongistatin 1: a synthetic strategy exploiting its latent pseudo-symmetry. Angew. Chem., Int. Ed. Engl. 2005, 44, 5433-5438.

28. O’Brien, M.; Diéguez-Vásquez, A.; Hsu, D.S.; Kraus, H.; Sumino, Y.; Ley, S.V. Azeotropic reflux chromatography: an efficient solution to difficult separation in the scale-up synthesis of spongistatin 1. Org. Biomol. Chem. 2008, 6, 1159-1164.

29. Favre, S.; Gerber-Lemaire, S.; Vogel, P. New efficient route to an advanced precursor of the AB spiroketal of spongistatins. Org. Lett. 2007, 9, 5107-5110.

30. Gerber-Lemaire, S.; Vogel, P. An expeditive asymmetric synthesis of polyfunctional 1,7dioxaspiro[5.5]undecanes. Eur. J. Org. Chem. 2004, 5040-5046.

31. Doubský, J.; Saman, D.; Zedník, J.; Vasíckova, S.; Koutek, B. A convenient access to thermodynamically nonstabilised spiroketal isomers: the first synthesis of (Z)-7-methyl-1,6dioxaspiro[4,5]decane. Tetrahedron Lett. 2005, 46, 7923-7926.

32. Corbet, M.; Bourdon, B.; Gueyrard, D.; Goekjian, P.G. A Julia olefination approach to the synthesis of functionalized enol ethers and their transformation into carbohydrate-derived spiroketals. Tetrahedron Lett. 2008, 49, 750-754.

33. Conway, J.C.; Urch, C.J.; Quayle, P.; Xu, J. Spiroketalization reactions on a carbohydrate template. Synlett 2006, 5, 776-780.

34. Potuzak, J.S.; Moilanen, S.B.; Tan, D.S. Stereocontrolled synthesis of spiroketals via a remarkable methanol-induced kinetic spirocyclization reaction. J. Am. Chem. Soc. 2005, 127, 13796-13797.

35. Moilanen, S.B.; Potuzak, J.S.; Tan, D.S. Stereocontrolled synthesis of spiroketals via Ti(O $i$-Pr $)_{4^{-}}$ mediated kinetic spirocyclization of glycal epoxides with retention of configuration. J. Am. Chem. Soc. 2006, 128, 1792-1793.

36. Fuwa, H.; Sasaki, M. An efficient strategy for the synthesis of endocyclic enol ethers and its application to the synthesis of spiroacetals. Org. Lett. 2008, 10, 2549-2552.

37. Shimizu, T.; Satoh, T.; Murakoshi, K.; Sodeoka, M. Asymmetric total synthesis of (-)spirofungin A and (+)-spirofungin B. Org. Lett. 2005, 7, 5573-5576. 
38. Paterson, I.; Anderson, E.A.; Findlay, A.D., Knappy, C.S. Total synthesis of pteridic acids A and B. Tetrahedron 2008, 64, 4768-4777.

39. Nakahata, T.; Fujimura, S.; Kuwahara, S. Total synthesis of pteridic acids A and B. Chem. Eur. J. 2006, 12, 4584-4593.

40. Takaoda, L. R.; Buckmelter, A. J.; La Cruz, T. E.; Rychnovsky, S. D. Rational Synthesis of Contra-Thermodynamic Spiroacetals by Reductive Cyclizations. J. Am. Chem. Soc. 2005, 127, 528-529.

41. For a recent review on synthetic approaches to Pectenotoxins see: Halim, R.; Brimble, M. A. Synthetic studies towards the pectenotoxins: a review. Org. Biomol. Chem. 2006, 4, 4048-4058. For recents synthetic efforts toward the spiroketal of Pectenotoxins see: a) O'Connor, P. D.; Knight, C. K.; Friedrich, D.; Peng, X.; Paquette, L. A. Pectenotoxin-2 Synthetic Studies. 3. Assessment of the Capacity for Stereocontrolled Cyclization To Form the Entire C1-C26 Subunit Based upon the Double Bond Geometry Across C15-C16. J. Org. Chem. 2007, 72, 1747-1754; b) Halim, R.; Brimble, M. A.; Merten, J. Synthesis of the ABC tricyclic fragment of the pectenotoxins via stereocontrolled cyclization of a c-hydroxyepoxide appended to the $\mathrm{AB}$ spiroacetal unit. Org. Biomol. Chem. 2006, 4, 1387-1399; c) Halim, R.; Brimble, M. A.; Merten, J. Synthesis of the ABC Fragment of the Pectenotoxins. Org. Lett. 2005, 7, 2659-2662; d) Bondar, D.; Liu, J.; Müller, T.; Paquette, L. A. Pectenotoxin-2 Synthetic Studies. 2. Construction and Conjoining of ABC and DE Eastern Hemisphere Subtargets. Org. Lett. 2005, 7, 1813-1816.

42. For a recent review on Attenol see: Kiyota, H. Synthesis of Marine Natural Products with Bicyclic and/or Spirocyclic Acetals. Top. Heterocycl. Chem. 2006, 5, 65-95.

43. Rychnovsky, S. D.; Jay, P.; Bowers, J. P.; LePage, T. J. Conformation and reactivity of anomeric radicals. J. Am. Chem. Soc. 1992, 114, 8375-8384.

44. Still, W. C.; Sreekumar, C. Alpha.-alkoxyorganolithium reagents. A new class of configurationally stable carbanions for organic synthesis. J. Am. Chem. Soc. 1980, 102, 12011202.

45. La Cruz, T. E.; Rychnovsky, S. D. A Reductive Cyclization Approach to Attenol A. J. Org. Chem. 2007, 72, 2602-2611.

46. Vellucci, D.; Rychnovsky, S. D. Diastereoselective Synthesis of the Pectenotoxin 2 NonAnomeric AB Spiroacetal. Org. Lett. 2007, 9, 711-714.

47. Pihko, P.M.; Aho, J.E. Access to Both Anomers of Pectenotoxin Spiroketals by Kinetic Spiroketalization. Org. Lett. 2004, 6, 3849-3852.

48. Castagnolo, D.; Breuer, I.; Pihko, P.M. Direct Kinetic Formation of Nonanomeric [6.5]Spiroketals in Aqueous Media. J. Org. Chem. 2007, 72, 10081-10087.

49. Tony, K. A.; Li, X.; Dabideen, D.; Li, J.; Mootoo, D. R. An iodoetherificationdehydroiodination strategy for the synthesis of complex spiroketals from dihydroxyalkene precursors. Org. Biomol. Chem. 2008, 6, 1165-1169.

50. Bedford, S. B.; Bell, E.; Bennet, F.; Haynes, C. J.; Knight, D. W.; Shaw, D. E. Model studies of the overall 5-endo-trig iodocyclization of homoallylic alcohols. J. Chem. Soc., Perkin Trans. 1, 1999, 2143-2153.

51. For reviews on the synthesis of marine polycyclic ethers, including ciguatoxins, see: a) Nakata, T. Total Synthesis of Marine Polycyclic Ethers. Chem. Rev. 2005, 105, 4314-4347; b) Sasaki, M. 
Recent Advances in Total Synthesis of Marine Polycyclic Ethers. Top. Heterocycl. Chem. 2006, $5,149-178$.

52. a) Domon, D.; Fujiwara, K.; Ohtaniuchi, Y.; Takezawa, A.; Takeda, S.; Kawasaki, H.; Murai, A.; Kawai, H.; Suzuki, T. Synthesis of the C42-C52 part of ciguatoxin CTX3C. Tetrahedron Lett. 2005, 46, 8279-83; b) Domon, D.; Fujiwara, K.; Murai, A.; Kawai, H.; Suzuki, T. Convergent synthesis of the IJKLM-ring part of ciguatoxin CTX3C. Tetrahedron Lett. 2005, 46, 8285-8288.

53. Beder, T.; Schuhmann, T.; Magull, J.; Grond, S.; von Zezschwitz, P. Comprehensive Study of Okaspirodiol: Characterization, Total Synthesis, and Biosynthesis of a New Metabolite from Streptomyces. J. Org. Chem. 2006, 71, 7125-7132.

54. Salim A. A.; Su, B-N.; Chai, H-B.; Riswan, S.; Kardono, L. B. S.; Ruskandi, A.; Farnsworth, N. R.; Swanson, S. M.; Kinghorn, A. D. Dioxadispiroketal compounds and a potential acyclic precursor from Amomum aculeatum. Tetrahedron Lett. 2007, 48, 1849-1853.

55. Peuchmaur, M.; Wong, Y-S. Studies towards the Synthesis of Aculeatin C. Synlett 2007, 29022906.

56. Heilmann, J.; Brun, R.; Mayr, S.; Rali, T.; Sticher, O. Minor cytotoxic and antibacterial compounds from the rhizomes of Amomum aculeatum. Phytochemistry 2001, 57, 1281-1285.

57. Heilmann, J.; Mayr, S.; Brun, R.; Rali, T.; Sticher, O. Antiprotozoal Acivity and Cytotoxicity of Novel 1,7-Dioxadispiro[5.1.5.2]pentadeca-9,12.dien-11-one Derivatives from Amomum aculeatum. Helv. Chim. Acta 2000, 83, 2939-2945.

58. Wong, Y-S. Synthesis of ( \pm )-aculeatins A and B. Chem. Commun. 2002, 686-687.

59. Falomir, E.; lvarez-Bercedo, P.; Carda, M.; Marco, J. A. Enantioselective synthesis and absolute configurations of aculeatins A and B. Tetrahedron Lett. 2005, 46, 8407-8410.

60. Alvarez-Bercedo, P.; Falomir, E.; Carda, M.; Marco, J. A. Enantioselective synthesis and absolute configurations of aculeatins A, B, D, and 6-epi-aculeatin D. Tetrahedron 2006, 62, 9641-9649.

61. Chandrasekhar, S.; Rambabu, C.; Shyamsunder, T. Total synthesis of aculeatins A and B via a tethered oxa-Michael approach. Tetrahedron Lett. 2007, 48, 4683-4685.

62. Peuchmaur, M.; Wong, Y-S. Diastereodivergent Strategies for the Synthesis of Homochiral Aculeatins. J. Org. Chem. 2007, 72, 5374-5379.

63. Baldwin, J. E.; Adlington, R. M.; Sham, V. W-W.; Marquez, R.; Bulger, P. G. Biomimetic synthesis of (G)-aculeatin D. Tetrahedron 2005, 61, 2353-2363.

(C) 2008 by the authors; licensee Molecular Diversity Preservation International, Basel, Switzerland. This article is an open-access article distributed under the terms and conditions of the Creative Commons Attribution license (http://creativecommons.org/licenses/by/3.0/). 